\title{
The acoustic climate of spaces located under overpasses in the context of adapting them for outdoor public events - a pilot case study
}

\author{
Elżbieta Komarzyńska-Świeściak ${ }^{1}$, Piotr Z. Kozłowski ${ }^{2}$ \\ ${ }^{1}$ Department of Public Architecture, Basics of Design, and Environmental Development; Faculty of \\ Architecture; Wrocław University of Science \& Technology; 53/55 Prusa, 50-317 Wroctaw, Poland; \\ elzbieta.komarzynska-swiesciak@pwr.edu.pl (D) 0000-0002-2688-4073 \\ ${ }^{2}$ Department of Acoustics, Multimedia and Signal Processing; Faculty of Electronics, Photonics \\ and Microsystems; Wroclaw University of Science \& Technology; \\ Wybrzeże Wyspiańskiego 27, 50-370 Wrocław, Poland; \\ piotr.kozlowski@pwr.edu.pl (D)0000-0002-3122-6606
}

Funding: This research received no external funding.

Abstract: Due to the current shortage of traditional public space because of its privatization, commercialization, and securitization, there is an urgent need to reclaim areas affected by motorized traffic in the urbanized areas. On the other hand, the process of adapting them for new purposes should be carefully carried out, addressing several issues, among them environmental acoustics. This study is meant to contribute to our understanding of acoustic conditions of a general model of the bridge underspace. Therefore, the aim of the research was to examine the existing acoustic climate by measuring noise levels and comparing them with equivalent acceptable noise levels for the expected type of space development and Noise Rating curves. In this research, a pilot case study approach was used, as measurements were taken for a chosen space located under an elevated road that represents certain criteria set by the researchers. The results allowed us to: (1) verify the relationship between the geometry of the bridge underspace and the noise levels, (2) assess the initial acoustic conditions in terms of possibilities of acoustic adaptation of the examined space for outdoor public events, and (3) formulate hypotheses and preliminary assumptions for the planned further and broader studies of the issues raised in this article. The presented results and their analysis show that it is possible to bring the acoustic conditions in the studied space to the state required for public or cultural meeting spaces. In comparison with earlier findings, the research undertaken appears to be pioneering and the results can be used as valuable input for further research on this topic.

Keywords: architectural and acoustical design, public space, bridge underspace, environmental acoustics, urban acoustics 


\section{Introduction}

The authors of this article are currently involved in an interdisciplinary research project focusing on examining to what extent existing space under bridge-like facilities (flyovers, viaducts, bridges) can be adapted for high-quality public space, dedicated especially for outdoor events, such as recreation and sport events, concerts, film screenings, lectures, etc. This research addresses several issues from various scientific disciplines such as, for example, urban planning, structural design, environmental engineering, and acoustics (Figure 1). The research undertaken appears to be pioneering and the results can be used as valuable input for further research on this topic, which has wide possibilities of use. Although the last decade has witnessed an increase in research interest in utilization of the bridge underspace, previous studies have failed to conduct in-depth analysis of its environmental conditions, especially in terms of possibilities of acoustic adaptation of this space for outdoor public events.

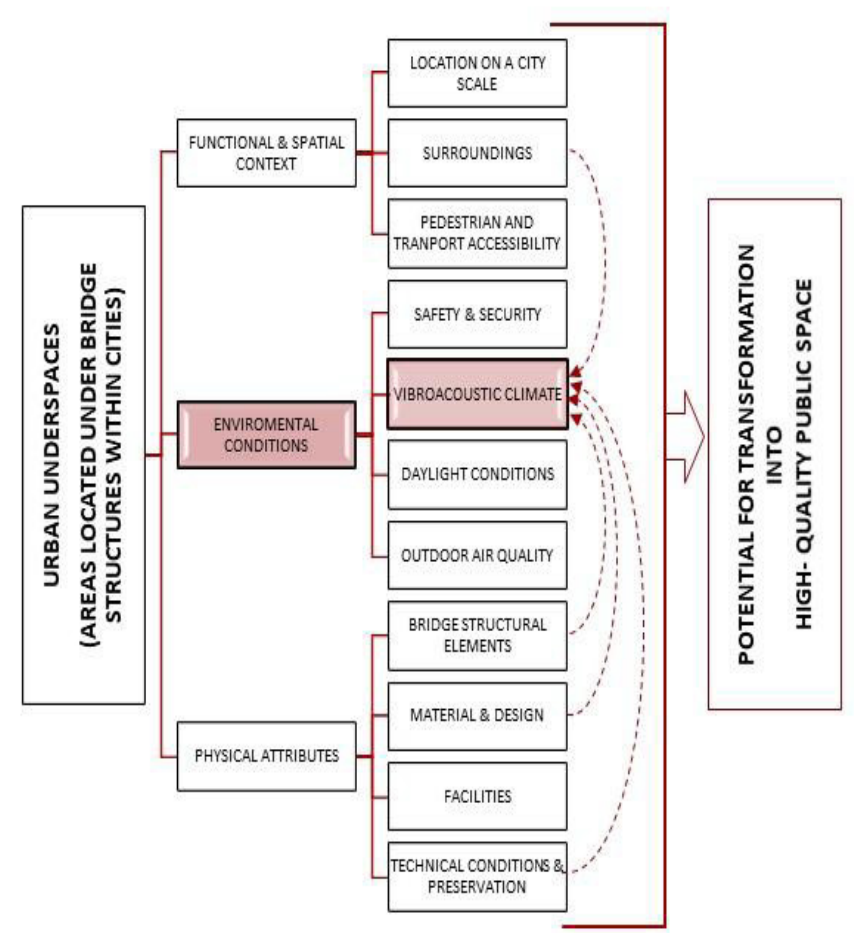

Fig. 1. Scheme of the interdisciplinary research project focusing on examining to what extent an existing space under flyovers, viaducts, and bridges can be transformed into high-quality public space. Colour indicates the focus of the analysis presented in the article. Source: authors' own elaboration

The article presents a selected case study that represents the starting point for the wider research on the acoustic climate within urban areas located under bridges, viaducts, and flyovers. The presented study is to contribute to our general understanding of acoustic conditions of a general model of the bridge underspace. Therefore, the authors started the research by describing the model scheme of the propagation of sound waves and vibrations under elevated infrastructure. In further stages, data were collected by measuring noise levels and comparing 
them with equivalent acceptable noise levels for the expected type of space development and Noise Rating curves. This allowed us to verify the relationship between the geometry of the bridge underspace and the noise levels, and assess the initial acoustic conditions in terms of possibilities of acoustic adaptation of the examined space for outdoor public events. The outcome of the presented research are also managerial recommendations in the form of hypotheses and preliminary assumptions for the planned further and broader studies of the issues raised in this article.

\section{Background of the study}

Nowadays there is a need to reclaim public space caused by the most contested issues in the contemporary transformation of public space: privatization, commercialization, and securitization [1]-[3]. Therefore, it is necessary to reclaim areas affected by motorized traffic (streets, rail and post-rail areas, transport nodes) located within the urbanized area and thus having high investment potential [4]-[7]. On the other hand, a possible resistance to use of spaces under a bridge for urban functions can be confronted with other current trends: the growing need for compact and sustainable cities [8] and urban regeneration of terrain vague areas where enclaves for social activities are increasingly created [9]. These types of urban transformations, also carried out in areas located under elevated transport routes, such as bridges, viaducts, and flyovers, can be a response to the deficit of social areas and the current crisis of traditional public space (Figure 2 and Figure 3). In this context, the hypothesis put forward by Komarzyńska-Świeściak [4] becomes even more valid, indicating an even greater need for interdisciplinary research on the adaptability of areas of transport conduits. In urbanized areas of European cities, bridge underspace located under elevated transit infrastructure is subject to functional and spatial transformations that can contribute to the regeneration of these public spaces and boost their attractiveness.

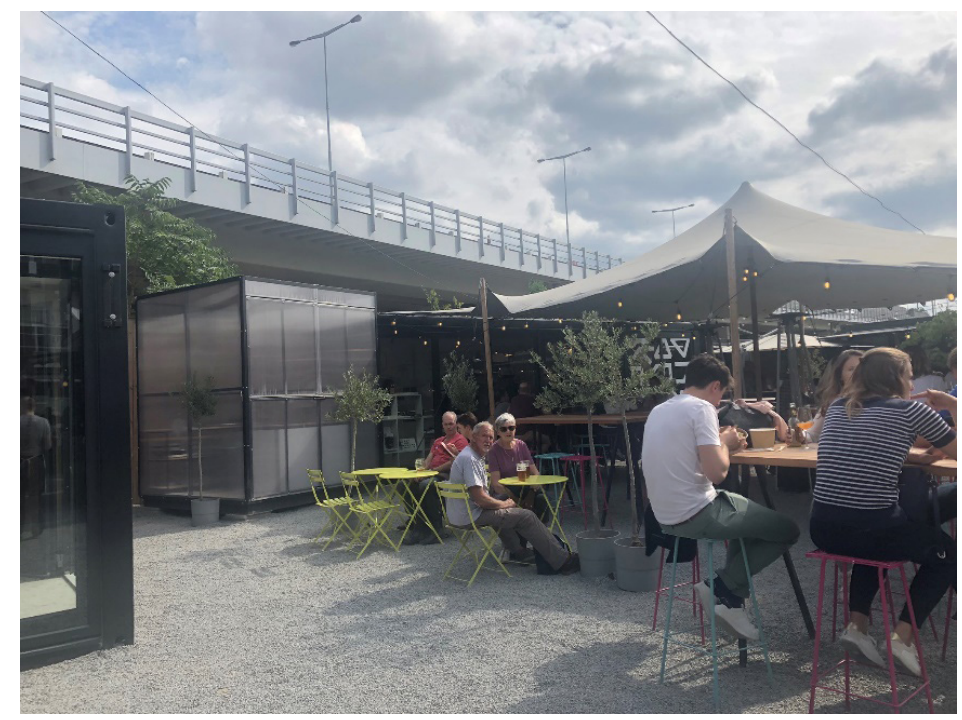

Fig. 2. Manifesto Market Florence - temporary industrial-chic dining \& drinking hub with more than 20 container stalls located under and nearby Wilsonova Flyover in Nové Město borough in Prague, 08.09.2019. Source: author's Elżbieta Komarzyńska-Świeściak own photo archive 


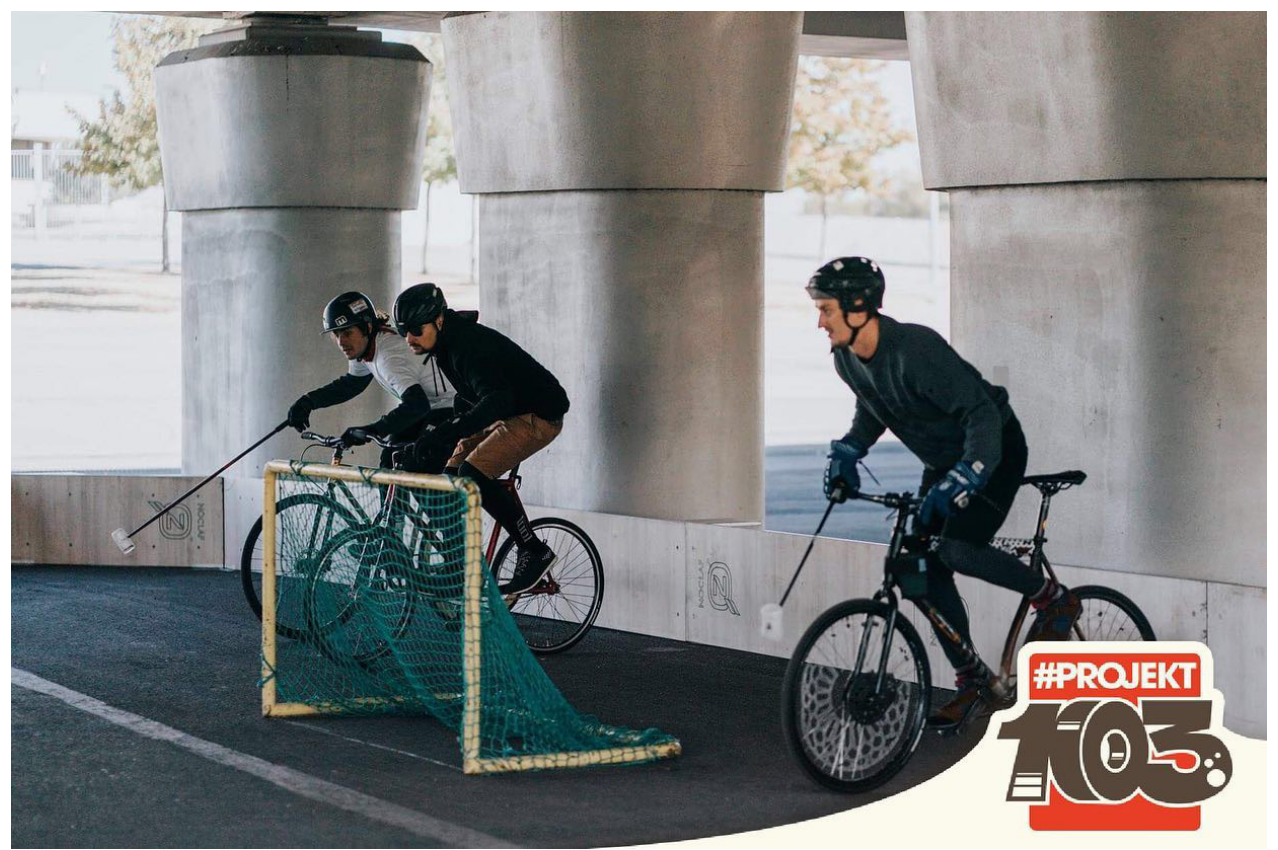

Fig. 3. Polish Bike Polo Championship organized within Temporary City Sports Centre - a recreation space arranged as a bottom-up initiative called \#Project103 under the flyover of Turowicza Street in Kraków. The Centre is planned to be built in 2022 in the same location thanks to financing gained from the civic budget of the City of Kraków [10]. Source: S. Barański

Ensuring a sense of safety and physical and psychological well-being for users of the bridge underspace, as with any other public space, is an essential condition for its proper utilization. On the other hand, some of characteristics of this space may not only enhance or reduce the impact of negative factors such as crime or traffic noise, but also affect the personal feelings of the person under the overhead traffic route. These areas have important constraints in this regard, for instance, they are usually poorly connected with urban tissue and are located near traffic routes. At the same time, studies of the literature show the rich collection of the examples of use of spaces located under elevated transit infrastructure, and architects and urban designers consider these spaces to have the potential to transform into pleasant and lively urban areas. Furthermore, the topicality of the research problem is confirmed by the results of literature analysis and field studies on 60 cases of European implementations of bridge underspace conducted by Komarzyńska-Świeściak in 2009-2017 [4], [10]. These examples show that proper retrofitting reduces their frightening, cold, and dark image and allow people to use them. Therefore, there is a need for research focusing on the baseline environmental conditions of the bridge underspace and the available solutions available minimizing the negative effects of environmental factors on the health and well-being of their users. 


\section{The literature review}

Although the last decade has witnessed an increase in research interest in the use of the bridge underspace, previous studies have failed to address in-depth studies of its environmental characteristics in light of its adaptive potential. The research shows that most of the literature has studied the transformation and utilization of the leftover space of overpasses from the perspective of an architect and urban planner, thus focusing mainly on land use and spatial forms. Moreover, these scientific works usually concern the analysis of the transformation of bridge underspace in certain geographical and cultural locations, e.g. Tokyo city [12]-[14] and Kuala Lumpur [15] or by limiting the analysis to a historical context [16]-[18]. The areas located under elevated transit infrastructure are also analyzed in publications on the interface between public spaces and transport routes [5], [19], [20] and on informal and bottom-up annexation of the city by local communities [21]. Furthermore, there are publications on the development of spaces under a bridge for green areas and landscape [22], [23]. However, most of the above-mentioned studies have overlooked environmental characteristics of the bridge underspace (e.g., acoustic climate, air quality, daylight access, health and safety issues) and their dependence from its unique spatial features, thus investigating whether they have potential to become safe and high-quality public spaces.

The study of the available literature shows that no comprehensive research has been conducted so far on the use of bridge underspace in the context of acoustics. Literature analysis shows that the published results of research on the vibroacoustic climate in such areas are very limited. There are publications devoted to the analysis of traffic noise at the level of the communication route [24], [25], [26], [27] but not of the areas below it (with the exception of cases where the route passes under a flyover, for example, [28]). On the other hand, there are studies on the noise generated by open-air concerts and events [29], [30], but there are no clear guidelines on the optimal vibration climate for such openair activities. Furthermore, the available data on the acoustic maps are inaccurate in the context of the presented study, as the measurements of the acoustic maps are carried out at the level of the elevated transport route, not below it [31], [32]. For a newly-designed urban space, to the knowledge of the authors, there are currently no binding legal acts or recommendations, even in the form of standards or recommendations, which would explicitly specify criteria to assess the baseline situation regarding noise and vibration level in underspaces. Some issues related to noise protection are regulated in Directive 2002/49/ EC [33], which specifies the allowable noise limit values in the environment. The areas for which the said acts set allowable noise limits include those intended for very vaguely defined recreational purposes. The authors of the article failed to find any publications in the literature review which would verify the acoustic climate in the bridge underspace exposed to the noise generated by the road traffic on a flyover. In the context of analyzing the usefulness of bridge underspace for creating recreational areas, the research presented below appears to be pioneering. Literature analysis, therefore, confirms that the issue is up-to-date and relevant and that attempts at finding solutions are needed. 


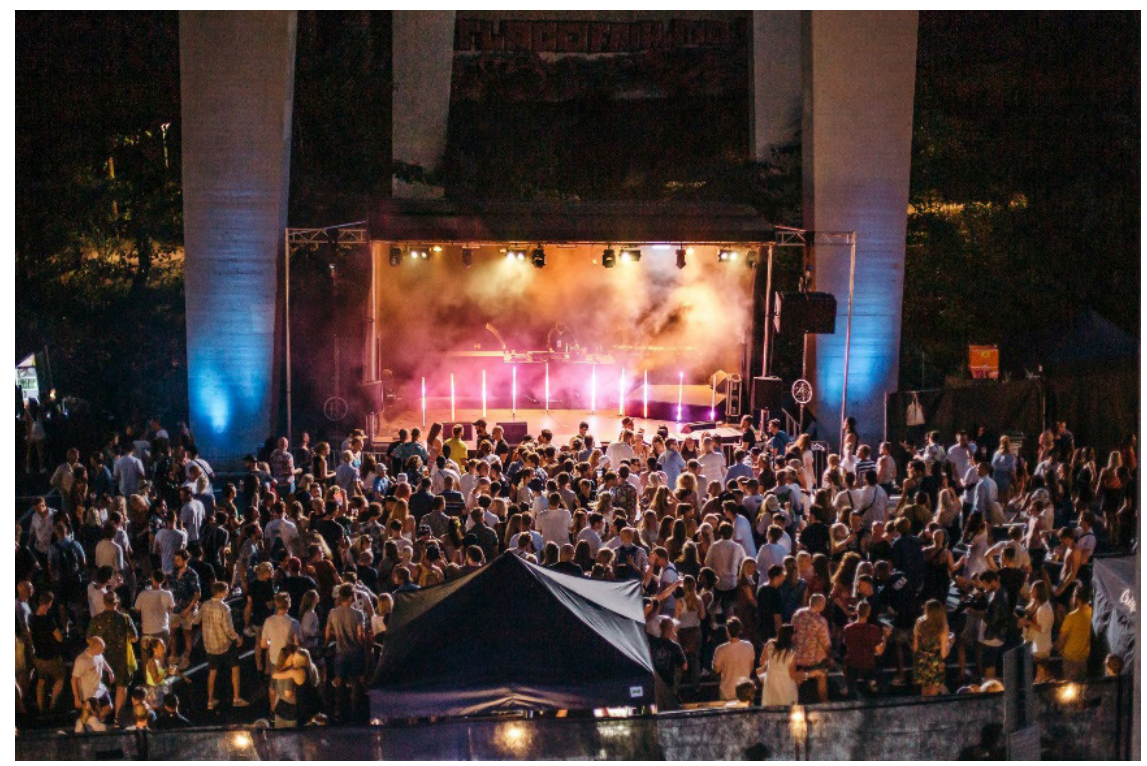

Fig. 4. Under The Bridge Music Festival organized annually under Ring 3 road flyover in the district Nydalen in the Nordre Aker borough in northern Oslo, 2019. Source: Thomas Refvik / Very Agency

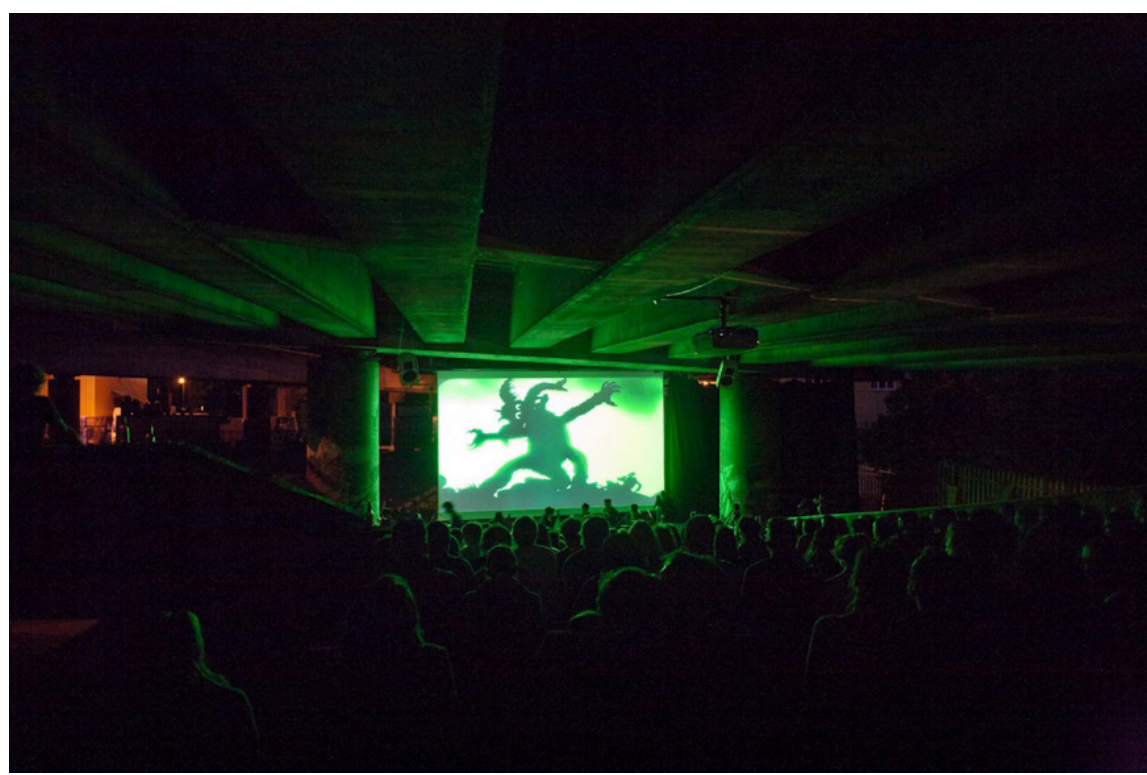

Fig. 5. A temporary cinema arranged for the community-engaging arts and culture event called Folly for a Flyover held in 2011 under the A12 flyover in the Hackney Wick area of London. Source: Assemble Studio

On the other hand, during research the authors noticed an increasing number of cases of use of bridge underspace for open-air concerts (e.g., 'Under The Bridge Music Festival' 
annually organized at several locations: New York, London, and Oslo (Figure 4), an international project 'Play Me, I'm yours' realized under the Westway flyover in London, a series of trumpet concerts by Piotr Damasiewicz performed under various bridges in Wrocław (Figure 8), theatre performances (e.g. the musical of Daniel Ottsa "Paulinenbrücke" presented under the road flyover in Stuttgart, performances of the 'Cirque du Soleil' group under the highway flyover in Québec and cinemas (e.g., 'Folly for a Flyover' festival in Hackney Wick in the area of London (Figure 5), KinoMost Czerniakowski Cape under Łazienkowski Bridge in Warsaw). The organizers of these events often justify their choice of this particular location by the unique acoustic conditions created by the structural elements of the flyovers (bridge slab, pillars) and water surface [34], although this has not been confirmed by any professional acoustic measurements.

\section{Materials and methods}

In the current research, a pilot case study approach was used as the measurements were taken for a chosen space located under an elevated road representing certain criteria set by the researchers. The presented small-scale preliminary study was conducted to formulate hypotheses about acoustic climate of bridge underspace and to evaluate feasibility and improve the study design prior to implementation of a full-scale research project. As the well-known research of Hartley [35] and Yin [36], the purpose of a case study is not to bring about generalizable findings, but to add to the field by providing a comprehensive understanding of the studied phenomenon (see [37]). In this respect, though the small sample and the context-dependent nature (see [38] on case studies) of this research prevent generalization, it does contribute significantly to the creation of new knowledge on the acoustic climate of areas located under elevated roads in the context of adapting them for public space. The presented case can be also used as valuable input for further research on this topic. That is why, the study's context and sample, and data sources and analyses are discussed more in-depth.

The obtained noise levels measurements in selected points of the examined bridge underspace were compared with equivalent acceptable noise levels $\left(\mathrm{L}_{\mathrm{A}, \text { eq }}\right)$ for the expected type of space development as defined in:

- WHO recommendations [39],

- regulations applicable in Poland [40].

The measurement results were also compared with NR (Noise Rating) curves, which define the maximum acceptable noise level in the given space. The family of NR curves was originally defined in ISO/R 1996:1971 [41] as the international standard for indicating acceptable sound levels within a space. NR curves are used in Europe, while the Noise Criterion (NC) family is more popular in the United States. Both curve families are used similarly and can be regarded as an interchangeable way of defining acceptable noise levels.

Interpretation of the results obtained at particular measurement points allowed us to verify the relationship between the geometry of the urban space under analysis (in particular: the location of the flyover deck in relation to the terrain and supporting elements) and the noise level. The obtained data allowed for assessing the initial acoustic conditions of a given space in terms of possibilities of acoustic adaptation of the examined space to serve selected functions. The analysis of the results also made it possible to determine the aims and scope of further research enabling detailed exploration of the issues raised in this article. 


\subsection{Noise level requirements}

The negative context associated with spaces in the immediate vicinity of elevated transport routes includes traffic-related noise and the vibrations of a bridge. The awareness of their negative impact on human health (both physiological and mental), makes urban planners avoid constructing of residential buildings, especially for long-term stay, as well as public spaces in the immediate vicinity of traffic routes. Traffic noise, in the form of sounds of air of excessive intensity caused by the major routes crossing central urban areas, is emitted by many individual sources, and thus depends on several factors: traffic volumes, the share of noisy vehicles (rail vehicles, lorries, buses, motorcycles) and vehicles in poor technical condition, traffic smoothness, condition of the road surface and roadways. Noise in the form of material sounds moves directly from the route structure to the ground and structurally connected buildings, if adequate road insulation is not provided.

For the following discussion, it should be noted that in accordance with the applicable regulations and guidelines, noise levels in public recreational areas should be minimized.

According to the regulations in force in Poland [40], the permissible level of noise caused by the roads for recreational areas for a reference time interval of 8 hours equal to the least favourable hours on consecutive days, $\mathrm{L}_{\mathrm{A}, \mathrm{eq}} \mathrm{D}$, is $55 \mathrm{~dB}$ A.

The WHO recommendations [39] clearly indicate that in open spaces used by people, $\mathrm{L}_{\mathrm{A}}$, eq noise level should not exceed $55 \mathrm{~dB} \mathrm{~A}$, and it is recommended that the optimum noise limit is $50 \mathrm{~dB}$. Detailed WHO recommendations state as follows:

1. The recommendations in Chapter 4.3.1 Dwellings [39] are as follows: "To protect the majority of people from being seriously annoyed during the daytime, the sound pressure level on balconies, terraces, and outdoor living areas should not exceed $55 \mathrm{~dB} \mathrm{~L}_{\mathrm{A} \text {, eq }}$ for a steady, continuous noise. To protect the majority of people from being moderately annoyed during the daytime, the outdoor sound pressure level should not exceed $50 \mathrm{~dB}$ $\mathrm{L}_{\mathrm{A}, \mathrm{eq}}$ ". These values are based on annoyance studies, but most countries in Europe have adopted $40 \mathrm{~dB} \mathrm{~L}_{\mathrm{A}, \text { eq }}$ as the maximum allowable level for new developments [42]. Indeed, the lower value should be considered the maximum allowable sound pressure level for all new developments whenever feasible".

2. The recommendations in Chapter 4.3.2 Schools and preschools [39] are as follows: "For outdoor playgrounds (at schools and preschools - added by the authors), the sound pressure level of the noise from external sources should not exceed $55 \mathrm{~dB} \mathrm{~L}_{\mathrm{A} \text {, eq }}$, the same value given for outdoor residential areas in the daytime".

The literature broadly discusses the expectations concerning permissible noise levels for architectural indoor spaces intended for the organization of concerts and lectures. The requirements for such spaces are based on the use of the so-called Noise Rating curves (NR) which determine the maximum acceptable noise level in a given space. These curves are commonly used by event venue designers to set requirements for concert, theatre, studio spaces in Europe, e.g. [43]. For outdoor public spaces, noise requirements are determined by means of single figure coefficients such as $\mathrm{L}_{\mathrm{A} \text {, eq. }}$. There are no guidelines for determining permissible noise by using noise curves in urban interiors. For this work, we used analogies with the requirements available in the specialist literature on event venues. The following recommendations can be found in these sources:

- indoor stadiums and gyms - NC/NR curve 40-55 [44],

- corridors, gyms NC/NR curve 35-45 - equivalent 45-55 dB A [45],

- swimming pools, sports arenas NC/NR curve 40-50 - equivalent 50-60 dB A [45]. 
Based on the above analysis of the cited literature, we assumed that for the purpose of adaptation to public recreational spaces, the following noise requirements should be met:

- noise level $\mathrm{L}_{\mathrm{A}, \mathrm{eq}} \leq 55 \mathrm{~dB}$ A,

- noise spectrum $\leq$ NR45.

\subsection{Scheme of the survey site}

To analyse the vibroacoustic climate of the theoretical bridge underspace model, the authors described and illustrated the sources of noise and traffic vibrations, as well as the propagation of acoustic waves under an elevated route (Figure 6) for an urban, bilaterally enclosed interior (the upper cover being a bridge and the lower being area beneath it). Such an interior cannot be completely isolated from the external environment, and the sound waves present there are subject to reflection, absorption, deflection, and interference. Common sources of interference associated with traffic noise and vibrations (identified by symbols $Z_{1}-Z_{3}$ ) generate air and shock (so-called material) sounds together with vibrations that reach an area located below the elevated road, respectively, in the form of the following waves:

- direct airborne noise wave (Wda), caused by traffic on a bridge $\left(Z_{1}\right.$ and $Z_{2}$ on Figure 6$)$ or a road in the bridge underspace $\left(\mathrm{Z}_{3}\right.$ on Figure 6$)$.

- reflected airborne noise wave (Wra), associated with a change of the direction of wave propagation, e.g., at the border with neighbouring buildings or structural elements (e.g., dilatation gaps in prefabricated constructions).

- partially absorbed airborne noise wave (Wpaa), for example thanks to green areas next to the road.

- direct structure-borne noise wave (Wd-sb), associated with structural vibrations caused by traffic on a bridge ( $\mathrm{Z}_{1}$ and $\mathrm{Z}_{2}$ in Figure 6 ) (the so-called audible material sounds).

- direct vibration wave (Wdv), linked to vibrations from road traffic (especially due to heavy and rail vehicles) and causing vibrations directly in the structural elements of a bridge.

- lateral transmission of vibration wave (Wltv), linked to the spread of the above-mentioned vibrations and so-called lateral transmission to subsequent interconnected elements, e.g., supports, ground, and construction facilities set there.

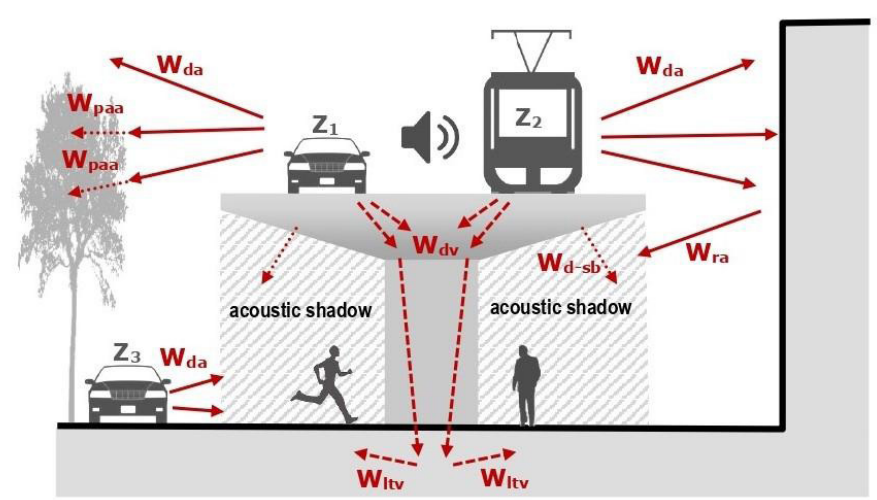

Fig. 6. Model scheme of the propagation of sound waves and vibrations under elevated infrastructure, e.g. flyover (individual symbols explained in the text). Source: authors'own elaboration 
In the presented diagram of sound wave and vibration propagation, it is a bridge plate that is of particular importance. Located between the source and receiver of the noise, it acts as a horizontal sound-reflecting screen, possibly partially absorbing air noise from road and rail traffic on a bridge (from source $\mathrm{Z}_{1}$ and $\mathrm{Z}_{2}$ ). This does not apply to shock sounds connected with vibrations generated directly in bridge structural components. In this case, the location under a bridge plate is a disadvantage because the vibration noise comes from the large effective radiation surface, which is bridge underside. In addition, as shown in [28], bridge underside greatly amplifies the noise due to reflection of the acoustic waves generated below the bridge underside. The reflection of the acoustic wave on the steel or concrete bridge underside not covered with any sound-absorbing materials can result in amplification of noise from side sources (Z3 in Figure 6) by up to $8 \mathrm{~dB}$.

The theoretical bridge underspace model shows that the given starting conditions depend not only on the characteristics and location of the source of sound and vibrations but also on the environment and the urban and architectural elements. Therefore, when analyzing the bridge underspace for new investment in the existing condition, a detailed analysis seems desirable. Such an analysis was performed for a selected bridge underspace.

\subsection{Survey site}

For case analysis, we selected a bridge underspace with a high potential for adaptation for recreational purposes, i.e. one that:

- has no major traffic route in its vicinity (in order to avoid a reflection of sound from the bridge underside [28]),

- in its neighbourhood there are some recreational (the Odra River, HotSpot city beach, walking, and cycling areas), residential (Port Popowice estate), as well as non-invasive services (indoor Orbita - WCT Spartan skating ring and the Orbita three-star hotel), which all indicate high investment potential of the plot,

- has a continuous/solid (without holes) bridge plate - shielding is provided,

- the existing land use under the bridge is not in the conflict with potential adaptation, and the land topography is even favourable to adaptation to, for example, the audience area (sloping ground),

- the geometry and size of the analyzed area allow for potential adaptation.

- the space has been already used for various outdoor social activities, e.g. movie making (Figure 7) and concerts (trumpet player Piotr Damasiewicz recorded a jazz song under Milenijny Bridge among many others Wrocław bridges, Figure 8). 


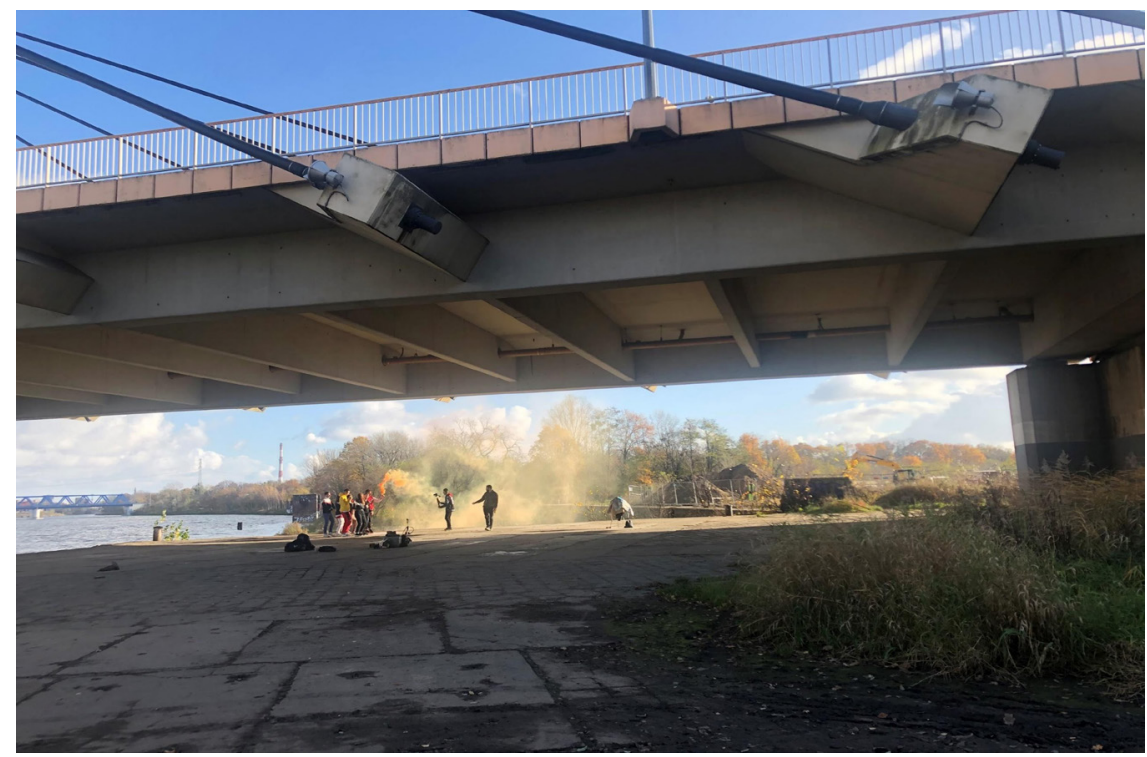

Fig. 7. Movie makers working on a video clip in the surroundings of the flyover construction elements in the area of the study. Milenijny Bridge (left-bank flyover) - span № 8, between $8^{\text {th }}$ axis and Odra river bank, 20.11.2020. Source: author's Elżbieta Komarzyńska-Świeściak own photo archive

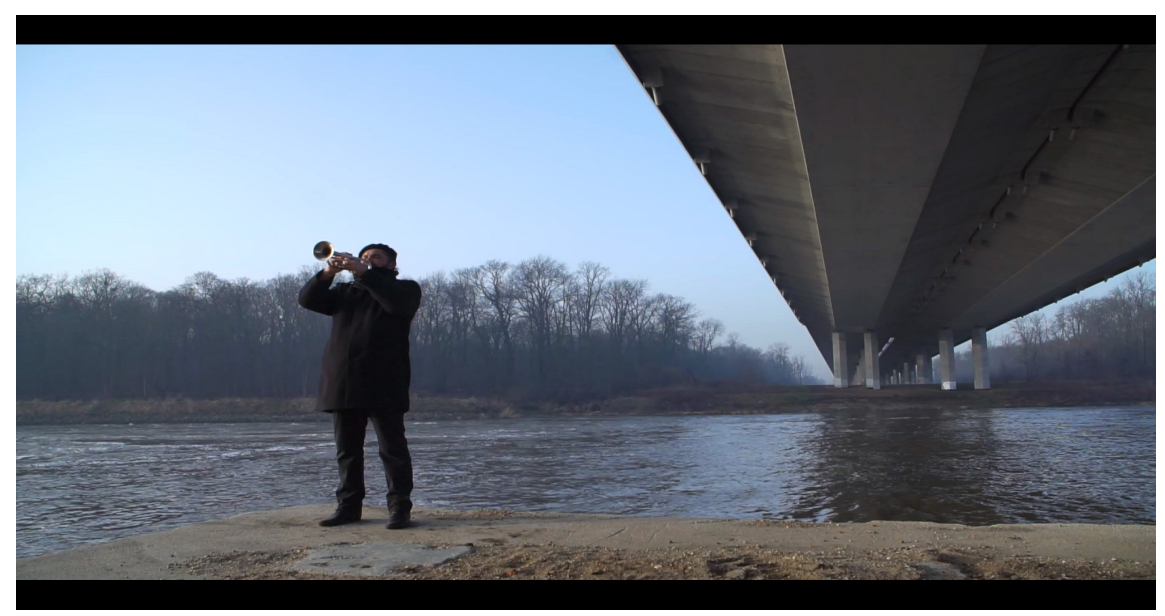

Fig. 8. The Sound of Wrocław Bridges - one of the trumpet concerts of Piotr Damasiewicz recorded on $25^{\text {th }}$ of February 2021 under Rędziński Bridge. Source: Adam Skórzewski and Tomasz Parużyński Musiat

The authors examined a stretch of about $25 \mathrm{~m}$ and about $90 \mathrm{~m}$ located under the left bank overpass of the Milenijny bridge (2 pylons in total) (Figure 9, Figure 10). The bridge structure is a reinforced concrete plate based on pairs of reinforced concrete pillars. The bridge has a bar support system and is placed on supports. The support on the pillars uses bearings and vibration isolators to prevent the transmission of vibrations to the pillars. On the $25.12 \mathrm{~m}$ wide bridge, there are two carriageways (with the width of $7 \mathrm{~m}$ each), two bicycle paths (with the width of $1.5 \mathrm{~m}$ each), and two pedestrian sidewalks (with the width of $2 \mathrm{~m}$ each) [46] (Figure 11). 

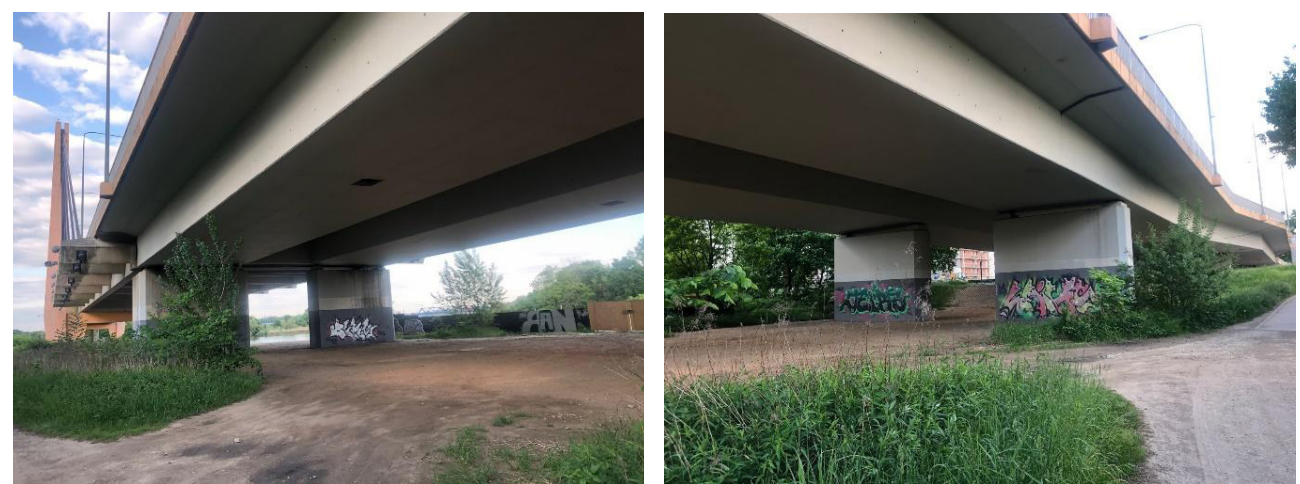

Fig. 9. Photos of the examined area. Milenijny Bridge (left-bank flyover) - crossing over the Odra River with access roads as part of the city-centre bypass, the section from Legnicka Street to Osobowicka Street, Wroclaw - span № 7, between $7^{\text {th }}$ and $8^{\text {th }}$ axis - measurement axis \#2. Source: author's Elżbieta Komarzyńska-Świeściak own photo archive
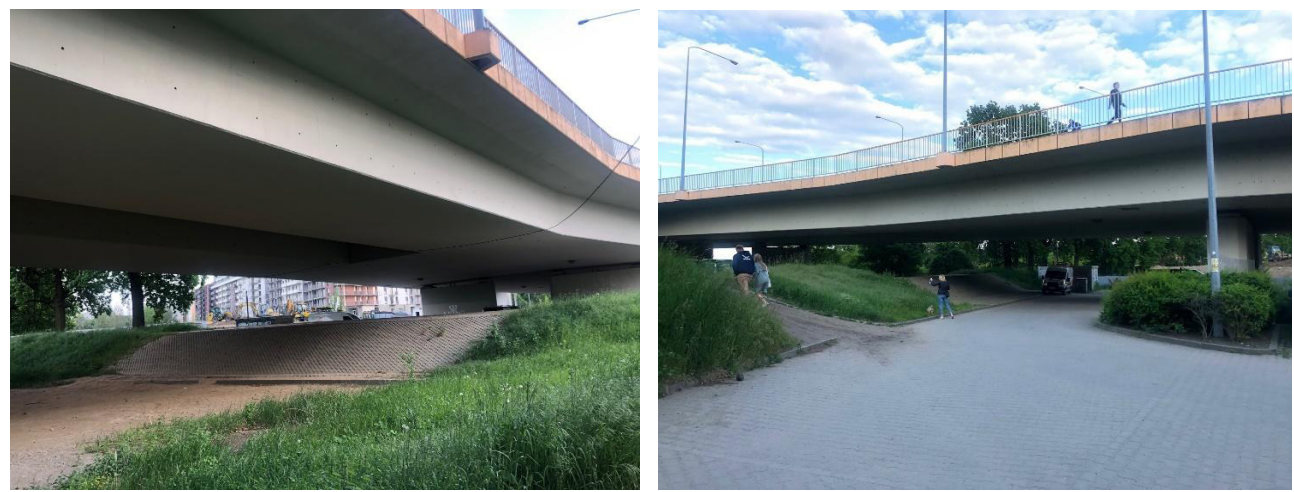

Fig. 10. Photos of the examined area. Milenijny Bridge (left-bank flyover) - crossing over the Odra River with access roads as part of the city-centre bypass, the section from Legnicka Streer to Osobowicka Street, Wroclaw - span № 6, between $6^{\text {th }}$ and $7^{\text {th }}$ axis - measurement axis \#1. Source: author's Elżbieta Komarzyńska-Świeściak own photo archive

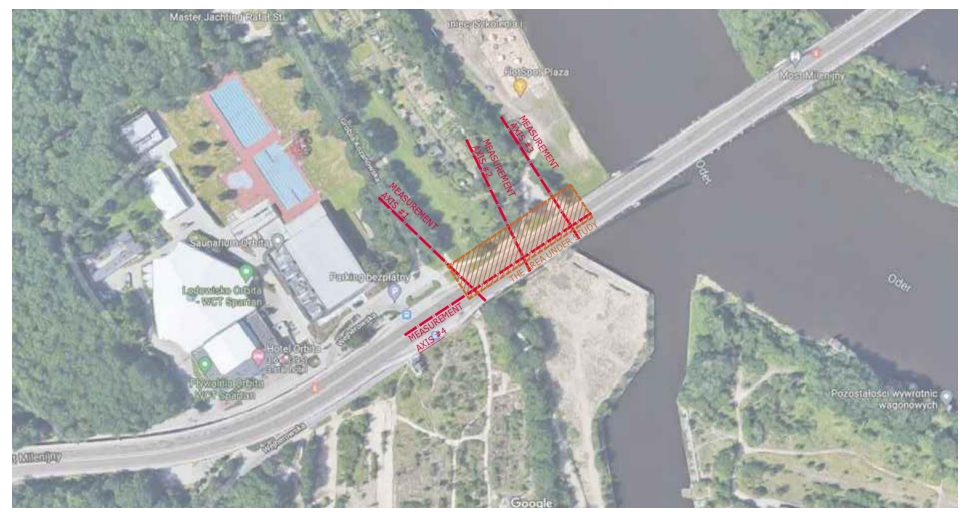

Fig. 11. The examined area - bird's eye view. Milenijny Bridge (left-bank flyover) - crossing over the Odra River with access roads as part of the city-centre bypass. Section from Legnicka Street to Osobowicka Street, Wroclaw. Source: authors'own elaboration 


\subsection{Research description}

The following schedule has been adopted for this research:

1. Specification of the selection criteria and selection of test facility.

2. Analysis of the design documentation of the selected test facility.

3. A preparatory session, during which test measurements were performed to determine the research plan.

4. A proper measurement session, the results of which are given in the text below.

Specialized vibration isolation solutions such as bearings, vibration pads, etc. are used for the flyover located over the analyzed area [46]. During the preparatory session, the authors confirmed that vibration insulation of the flyover structure works as intended so that no noticeable vibration of the flyover poles up to $2 \mathrm{~m}$ from the ground level was detected. Based on this preliminary test, the authors decided not to carry out vibration tests for the test facility, because they were virtually absent there.

During the measurements, sound levels were measured as broadband and for terce bands (1/3 of an octave). In all the cases, equivalent values measured for 10 minutes are given. The measurements taken during the preparation session confirmed that an increase in the measurement time of more than 10 minutes does not result in noticeable changes in the results obtained.

During the preparatory session, the authors noted that the predominant noise component in the examined space under the flyover is the noise caused by road traffic on four lanes on the flyover. The effect on the results of minor traffic on local roads located on the ground near measuring axis \#1 is negligible. However, the authors noted that intensification of noisy works in the nearby residential construction site resulted in an increase in noise measured in the examined space under the flyover. Even though there is a greater distance from the test area to the construction site than to the carriageways, where the dominant component noise component was generated, the incidental noise from the construction site was clearly perceived. This is because of reflection of sound waves on the underside of the flyover; a similar situation was described by Chi-Chwen et al. [28]. During the proper measurement session, the authors avoided taking measurements during the incidental increase in noise levels from the site. Thus, the presented results can be considered as relating mainly to noise caused by road traffic on the flyover.

There are no elements on the bridge that could absorb noise; for example, green belts. The analyzed area under the flyover is partially green and partially paved. On the sides of the flyover, there are some individual trees in a number and distance virtually excluding their influence on the acoustic environment beneath the flyover. There are no buildings in the vicinity of the test areas which should be considered as elements that reflect the acoustic waves generated on the flyover. After considering the structure and surroundings of the analyzed facility, the authors were able to adopt a simplified model for the propagation of noise in the bridge underspace shown in Figure 12. 


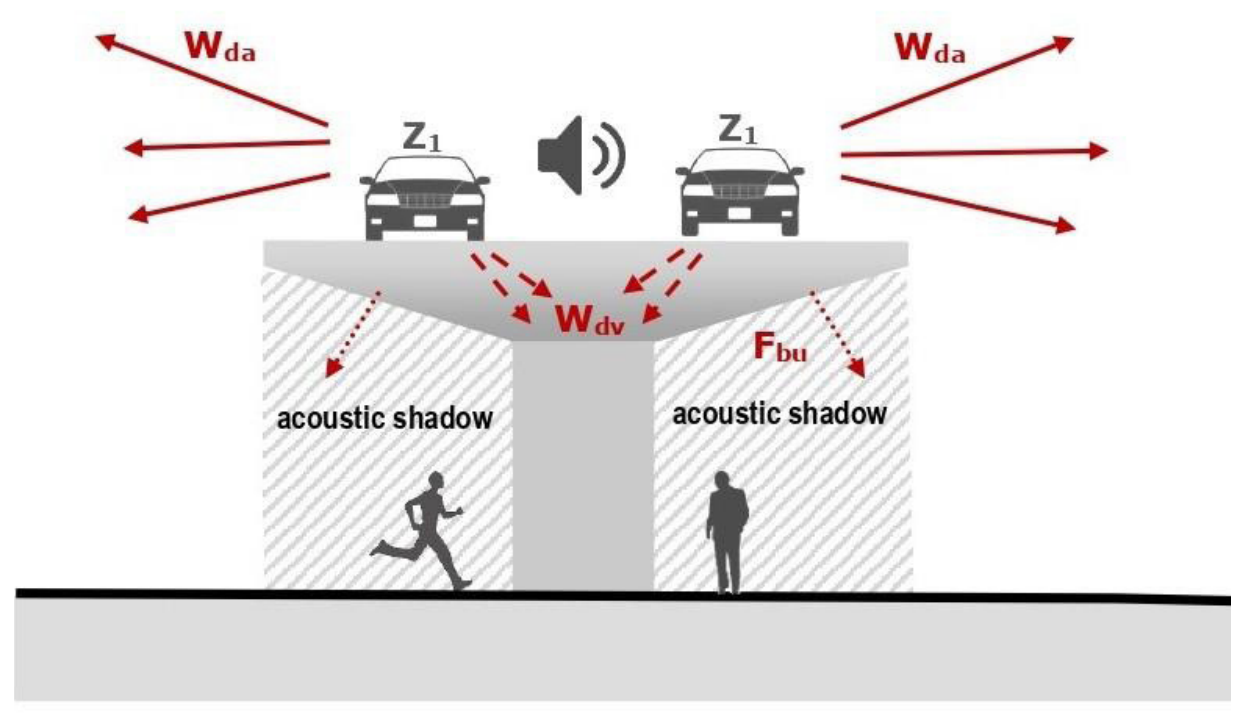

Fig. 12. Model scheme of the propagation of sound waves and vibrations in the area of the study - Milenijny Bridge (left-bank flyover) - crossing over the Odra River with access roads as part of the city-centre bypass, the section from Legnicka Street to Osobowicka Street, Wroclaw. Source: authors' own elaboration

In the test area shown in Figure 11, four measuring axes (\#1 - \#4) with four measurement points each were selected. The location of the axes and the individual measurement points are shown in the projection presented in Figure 13.

For axes $\# 1-\# 3$, the location of the individual measurement points is determined as in the following diagram, where $*$ is the axis number:

- points with an $\mathrm{R}^{*} .1$ index were on the axis of the entire flyover,

- points $\mathrm{R}^{*} .2$ were located under the carriageway axis,

- points $\mathrm{R}^{*} .3$ were located under the flyover edge,

- points $\mathrm{R}^{*} .4$ were located outside the flyover at a distance from the $\mathrm{R}^{*} .3$ point (flyover edge) equal to the distance between the $R^{*} .1$ points (flyover axis) $-R^{*} .3$ (flyover edge).

This arrangement scheme was chosen to check the effect of shielding traffic noise by the flyover. A comparison of the measurement results for individual points within a single axis provides an answer to the question whether the location of new functions of the bridge underspace is sensible from the point of view of protection from the road noise point resulting from the traffic on the flyover. 


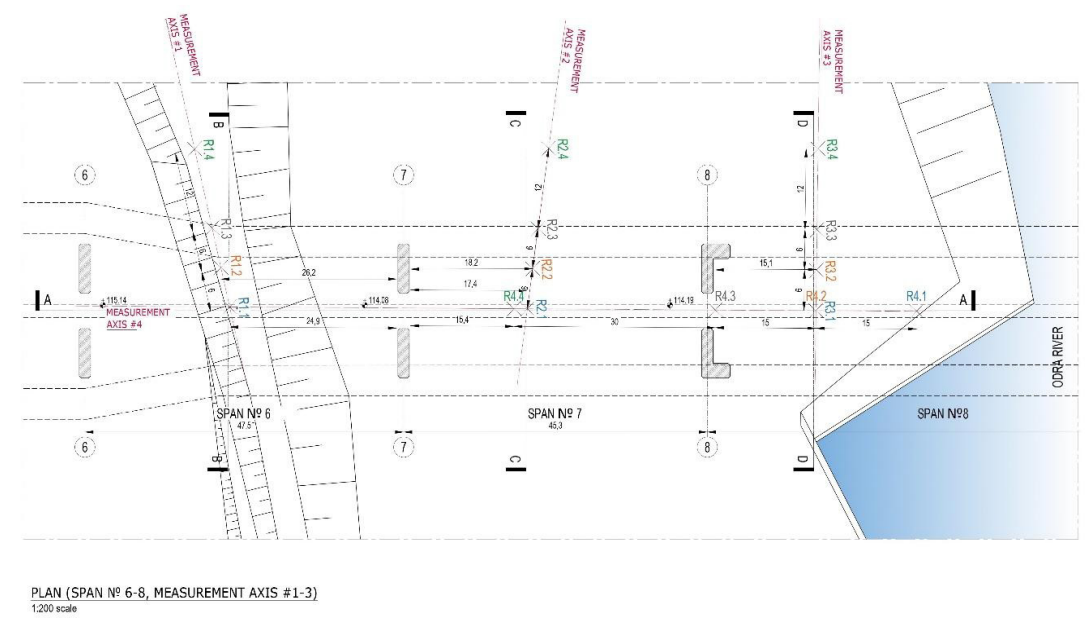

Fig. 13. The area of the study - plan. Milenijny Bridge (left-bank flyover) - crossing over the Odra River with access roads as a part of the city-centre bypass. Section from Legnicka Street to Osobowicka Street, Wroclaw. Source: authors'own elaboration, based on [46]

The measurement axis \#1 was drawn along a paved walking/cycling path passing almost perpendicular to the flyover axis (Figure 14). In this case, from all the measurements made the flyover underside was closest to the measuring microphones. For the R1.1 and R1.3 points, the flyover underside was $5.8 \mathrm{~m}$ above the path, whereas for the R1.2 point, it was $3.5 \mathrm{~m}$ above the path. This means that the measuring points were placed $4.3 \mathrm{~m}$ and $2 \mathrm{~m}$ under the flyover respectively.

The measurement axis \#2 has been positioned between the successive flyover supports on unpaved ground (Figure 15). In this axis, the flyover was higher over the ground than in the case with measurement axis \#1. The distance between the ground and the concrete flyover underside was $8.5 \mathrm{~m}$ for points R2.1 and R2.3 and $6.2 \mathrm{~m}$ for point R2.2, which yields the distance of the measuring microphones from the flyover underside of respectively $7 \mathrm{~m}$ and $4.7 \mathrm{~m}$.

The measurement axis \#3 was placed between the river banks and the subsequent flyover supports (Figure 16). In this place, the ground is paved with concrete slabs typical for construction sites. For this axis, the distance from the flyover underside to the ground was the largest of all the measurement axes and it was $9 \mathrm{~m}$. This means that the distance from the flyover underside to the measuring microphones was $7.5 \mathrm{~m}$.

The differences in location of measurement axes \#1 - \#3 were intended to verify the effect of the distance between the ground and the flyover underside on the resultant noise level. In addition, with such an arrangement of measurement axes, it was possible to determine whether, for the examined flyover, the noise level depends on the ground material (the cobbled pavement near the lawn and cobbled parking lot, unpaved ground, extensive ground paved with concrete slabs in the vicinity of the river).

The measurement axis \#4 is located below the flyover central line (Figure 17). The R4.1 point was located near the edge, $30 \mathrm{~m}$ from the nearest pylon. The R4.3 point was in the immediate vicinity of the flyover supports. The R4.4 point was in two-thirds of the distance between successive supports, i.e. $30 \mathrm{~m}$ from one support and $15 \mathrm{~m}$ from 
the next one. The location of the measurement points on axis \#4 was intended to check whether for the tested flyover the noise level or its spectrum differs as a function of distance from the river and coming closer to the structural supports. For axis \#4, for the individual measurement points the distance from the flyover bottom to the ground in the case of axis \#4 was as follows: R4.1 - $9.1 \mathrm{~m}, \mathrm{R} 4.2$ - $9 \mathrm{~m}, \mathrm{R} 4.3-9.1 \mathrm{~m}, \mathrm{R} 4.4-8.7 \mathrm{~m}$; thus, the distance between the flyover bottom and microphones was $7.6 \mathrm{~m}, 7.5 \mathrm{~m}, 7.6 \mathrm{~m}$ and $7.2 \mathrm{~m}$ respectively.

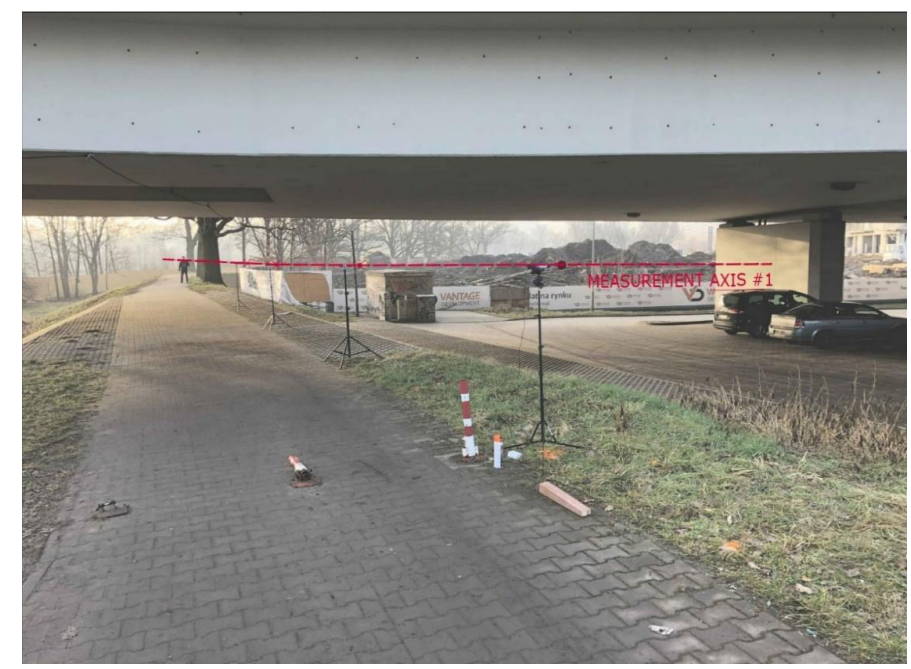

Fig. 14. Axis \#1 was placed along the pavement located on the slope in the area of the paved parking area and the lawn located below. Source: author's Piotr Kozłowski own photo archive

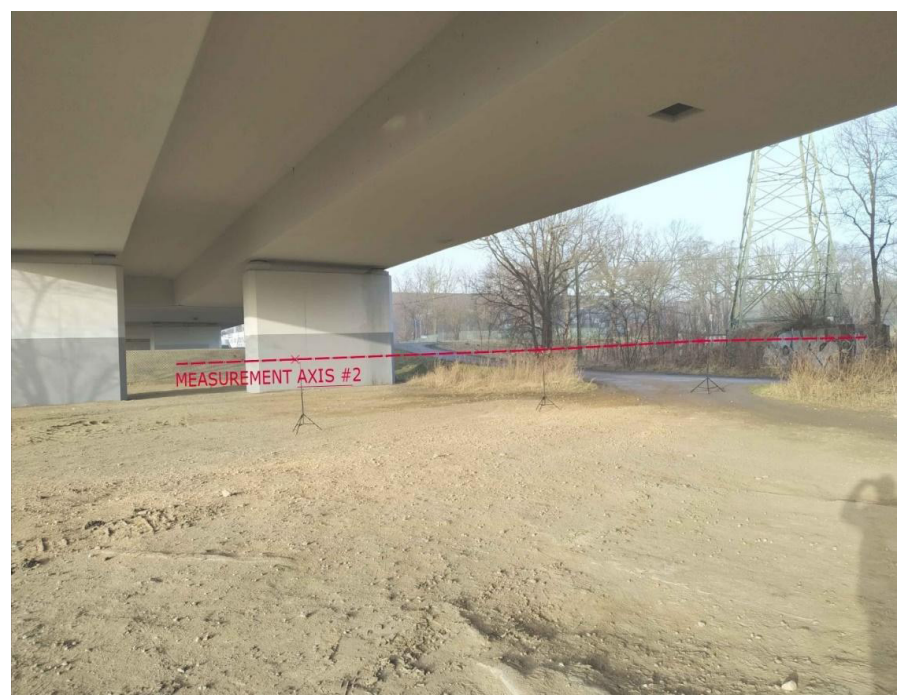

Fig. 15. Axis \#2 was placed on unpaved ground (below the slope). Source: author's Piotr Kozłowski own photo archive 


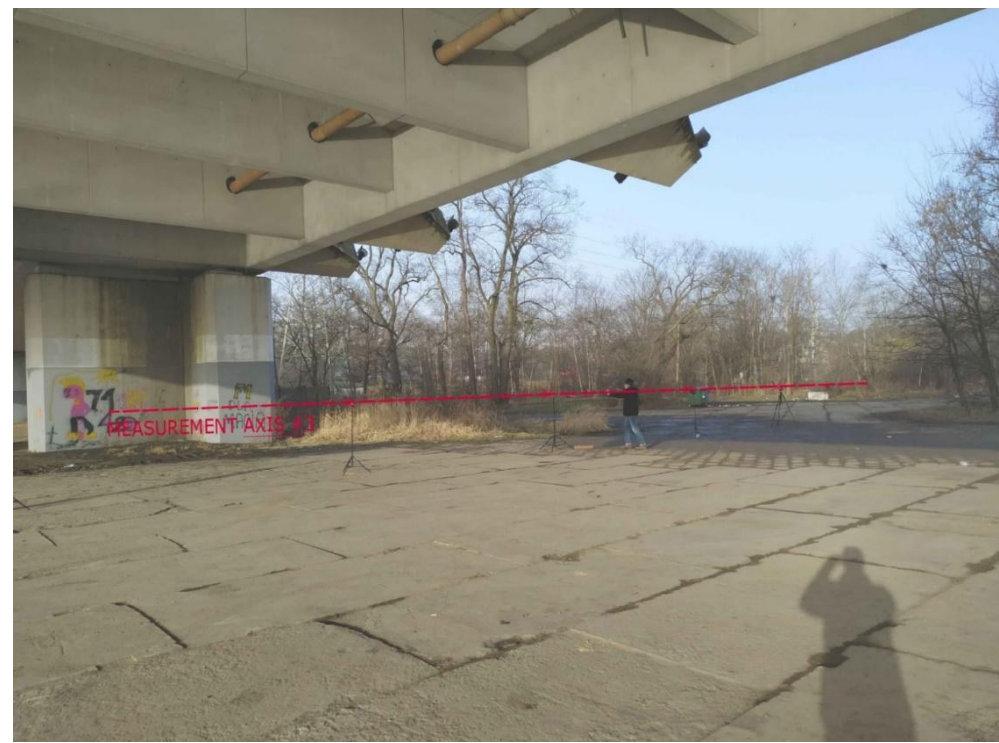

Fig. 16. Axis \#3 was placed near the river bank on the area paved with concrete slabs (below the slope). Source: author's Piotr Kozlowski own photo archive

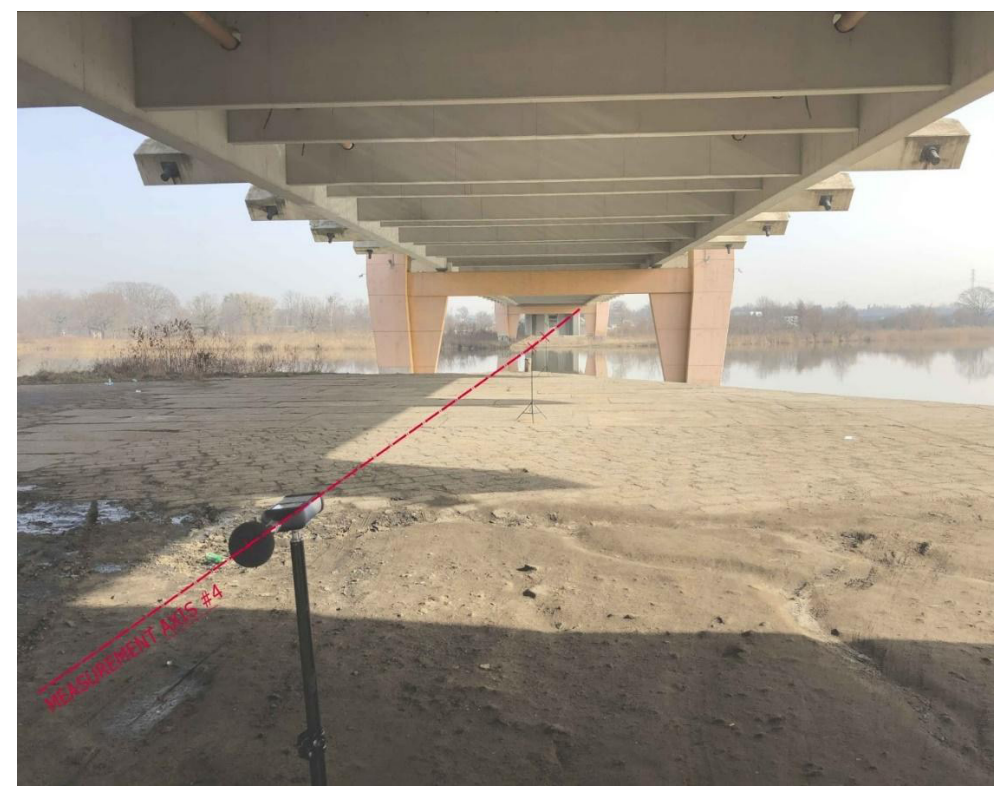

Fig. 17. Axis \#4 was placed along the flyover partly on unpaved ground and on ground paved with concrete slabs. Source: author's Piotr Kozłowski own photo archive

The Svan971, Svan945A, and Svan979 sound meters were used for the tests. All meters were calibrated using the factory calibrators included in each of the measurement sets. The 
calibration was made before and directly after completing the measurements. Calibration corrections are included in the presented results. The meters have been placed on independent tripods in such a way that the measuring microphones were $150 \mathrm{~cm}$ above the ground, which means that the measurement situation corresponded to a standing eye level. All meters were battery-powered. The distances between the measurement points and the flyover elements were measured using a laser distance meter and measuring tape.

The tests were conducted during the morning rush hours on a working day to verify the acoustic conditions of the chosen location in the worst possible conditions when the highest possible noise levels may occur. Measurements started at 07:00 a.m. Measurement series for measurement axis \#1 was performed first. Then, the authors proceeded to the series of measurements for axis \#2, \#3, and \#4. After that, a second series of measurements for all axes $\# 1-\# 4$ were performed. Finally, the third series of measurements was performed for all axes \#1 - \#4. This test schedule allowed for even allocation of top traffic intensity periods, i.e. just after 7 a.m., and lower traffic intensity periods, i.e. time before 11 a.m., among the measurement axes.

\section{Results}

The maximum difference in the equivalent $\mathrm{L}_{\mathrm{A}, \mathrm{eq}}$ values measured in successive series at the same measurement points do not exceed $3 \mathrm{~dB}$. This means for the test area under the flyover of the city bypass that stable noise conditions occur from morning to noon. Due to small differences observed between the results obtained in each measurement series, the authors decided not to include all the partial results for each series separately here, but to use the final results, which are the averages of all series. The values shown in the diagrams below were obtained by averaging the measurement results for each measuring point and each terce band independently. The equivalent broadband sound levels $\mathrm{L}_{\mathrm{A} \text {, eq }}$ presented here are also the result of energy averaging of the values indicated by the sound meters in subsequent measurement series.

As already mentioned earlier on the basis of literature studies, the authors assumed that the maximum permissible noise in the test space, after adaptation for public recreational purposes, expressed as a single-figure factor should not exceed $\mathrm{L}_{\mathrm{A}, \mathrm{eq}}=55 \mathrm{~dB}$ a, while the determined noise curve should meet the NR45 criterion.

Figure 18 and Figure 19 present sectional views of measurement axes $\# 1$ - \#4 with the $\mathrm{L}_{\mathrm{A}}$, eq values at individual measurement points. This visualization allows us to easily link the results obtained to the location of the measured noise levels.

Analysis of the results presented in Figure 18 and Figure 19 shows that no significant increase in noise levels was observed at measurement points extended under the flyover. This proves that the phenomenon of wave deflection at the flyover edge is not strong enough to limit new functions of the tested bridge underspace only to the surface located directly under the bridges. Moreover, no clear differences of the noise levels measured were found in the test areas under the central line of the flyover and those clearly extending under the flyover. Only for axis \#3 the authors noticed an increase of $4 \mathrm{~dB}$ of noise for the measurement point located outside the direct flyover underspace. For axis \#3, it is rather the effect of lack of noise attenuation by the ground due to large surface paved with concrete plates and the greatest distance from the measurement points to the flyover underside.

For axis \#1, the differences in noise levels measured at each point do not exceed $1 \mathrm{~dB}$, which is the greatest level of noise alignment in these measurements. This may be because the \#1 axis has the smallest distance between the measurement microphones and the flyover underside. 
Analysis of the graphs shown in Figure 18 and Figure 19 indicates that measured $\mathrm{L}_{\mathrm{A} \text {, eq }}$ values range from 62 to $69 \mathrm{~dB}$ A, which means that noise in the test space exceeds recommendations and requirements by 7 to $14 \mathrm{~dB}$ in a broadband.

It is worth mentioning that the highest levels were recorded in two cases:

- when point R3.4 was above the ground paved with concrete plates at the greatest distance from the bridge plate,

- when point R4.3 was very close to the concrete pillars reflecting acoustic waves.

In Figure 26 it can be seen that point R4.3 is characterized by a clear increase in noise level at frequencies above $2 \mathrm{kHz}$.

In other words, local increase of noise level is expected in areas in vicinity of large reflective concrete surfaces. This, in turn, confirms the justness of the following actions:

- assembly of broadband sound-absorbing systems on sound-reflecting components such as pillars and flyover underside,

- avoiding, as much as possible, ground pavement in areas where this is not necessary due to functional requirements.

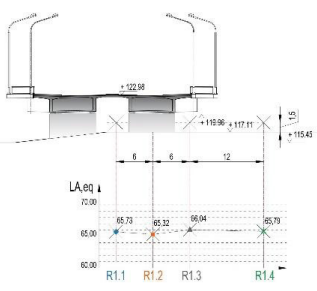

SECTION B-B (SPAN No 6, MEASUREMENT AXIS \#1)

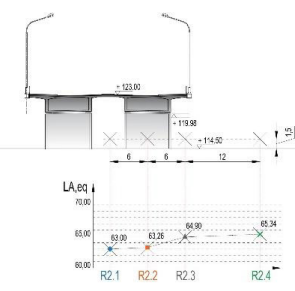

SECTION C-C (SPAN NO 7, MEASUREMENT AXIS \#2)

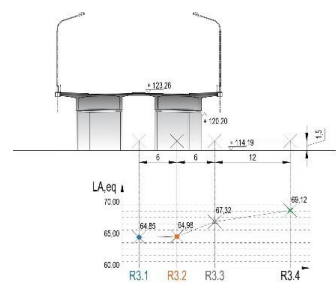

SECTION D-D

(SPAN NO 8, MEASUREMENT AXIS \#3)

Fig. 18. Cross-sections compiled with graphs illustrating the $\mathrm{L}_{\mathrm{A}, \mathrm{eq}}$ parameter (equivalent SPL A-weighted) obtained at each measurement point: A. Cross-section B-B compiled with averaged results of three measurement sessions on axis \#1. B. Cross-section C-C compared with averaged results of three measurement sessions on axis \#2. C. Cross-section D-D illustrated with averaged results of three sessions on axis \#3. Source: authors' own elaboration based on [46]

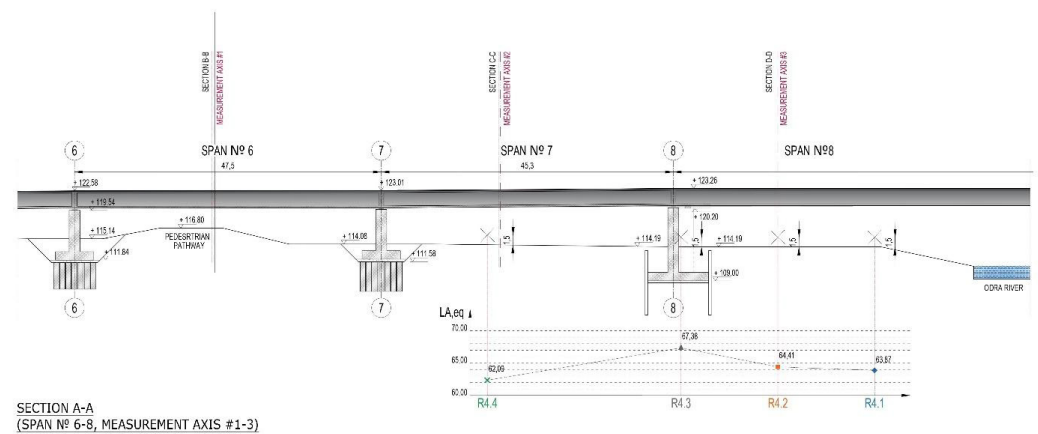

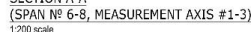

Fig. 19. Longitudinal section A-A compiled with a graph illustrating the $\mathrm{L}_{\mathrm{A}, \mathrm{eq}}$ parameter (equivalent $\mathrm{SPL}$ A-weighted) obtained as an averaging of the values measured in the three sessions at individual measurement points R4.1-R4.4. Source: authors' own elaboration based on [46] 
Figure 20, Figure 22, Figure 24 and Figure 26 present noise spectra for all the Rx.1 Rx.4 measurement points on the individual \#1 - \#4 measurement axes. Such presentation of the results makes it possible to check which spectral differences occurred between the individual measurement points.

The graphs shown in Figure 21, Figure 23, Figure 25, and Figure 27 presenting the averaged characteristics of frequency for all the four points of a given measurement axis compared with the lowest NR noise curve met by the background noise determined in this way and the NR45 curve. Such presentation of data allows for clear visualization of what noise conditions expressed by NR curves can be currently found in the test location and what noise reduction measures should be taken to meet the requirement defined in NR45.

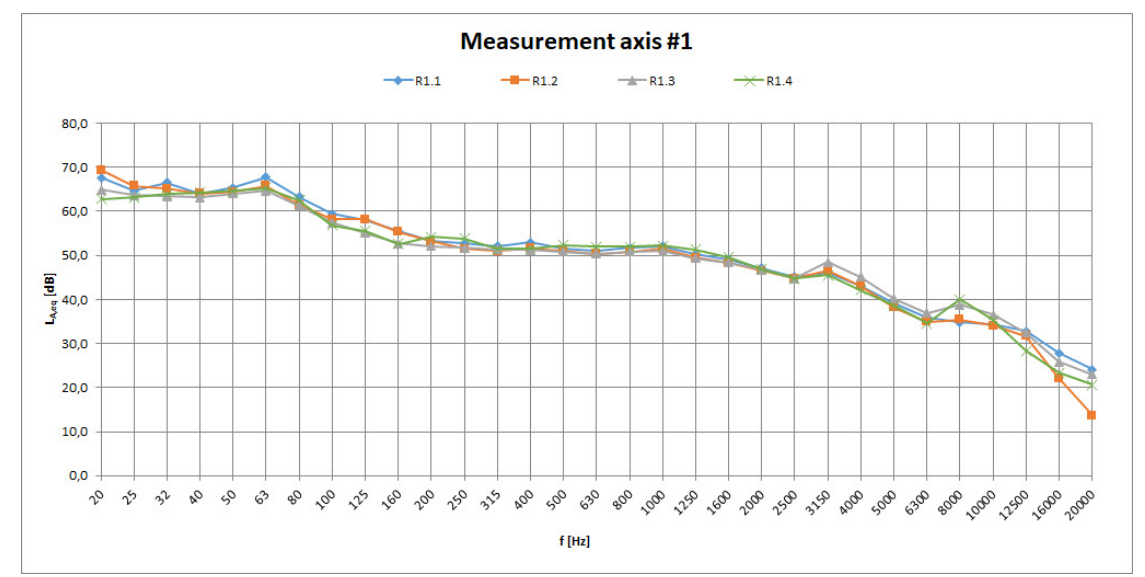

Fig. 20. Results of measurements taken at every measurement point (R1.1 - R1.4) at axis \#1. Equivalent value (10 minutes) of SPL A-weighted $\mathrm{L}_{\mathrm{A}, \text { eq }}$ in the function of frequency f. Source: authors' own elaboration

For axis \#1, not only the single-figure $\mathrm{L}_{\mathrm{A}}$, eq levels but also the noise spectrum proved to be very similar for all the measurement points (R1.1 - R1.4). Figure 11 indicates that the noise level for this axis is exceeded by $11 \mathrm{~dB}$ A. Figure 21 shows that the limit values are exceeded for octave bands over $125 \mathrm{~Hz}$. Relatively smallest exceedance of noise limits occurs for frequency band $1 / 1$ octave, $8 \mathrm{kHz}$. Significant noise exceedances were recorded for the $250 \mathrm{~Hz}$ to $4 \mathrm{kHz}$ bands, with a maximum of $1 \mathrm{kHz}$ octave, resulting in the noise on the $\# 1$ axis being finally described by the NR56 curve, which is $11 \mathrm{~dB}$ higher than the allowable limit. 


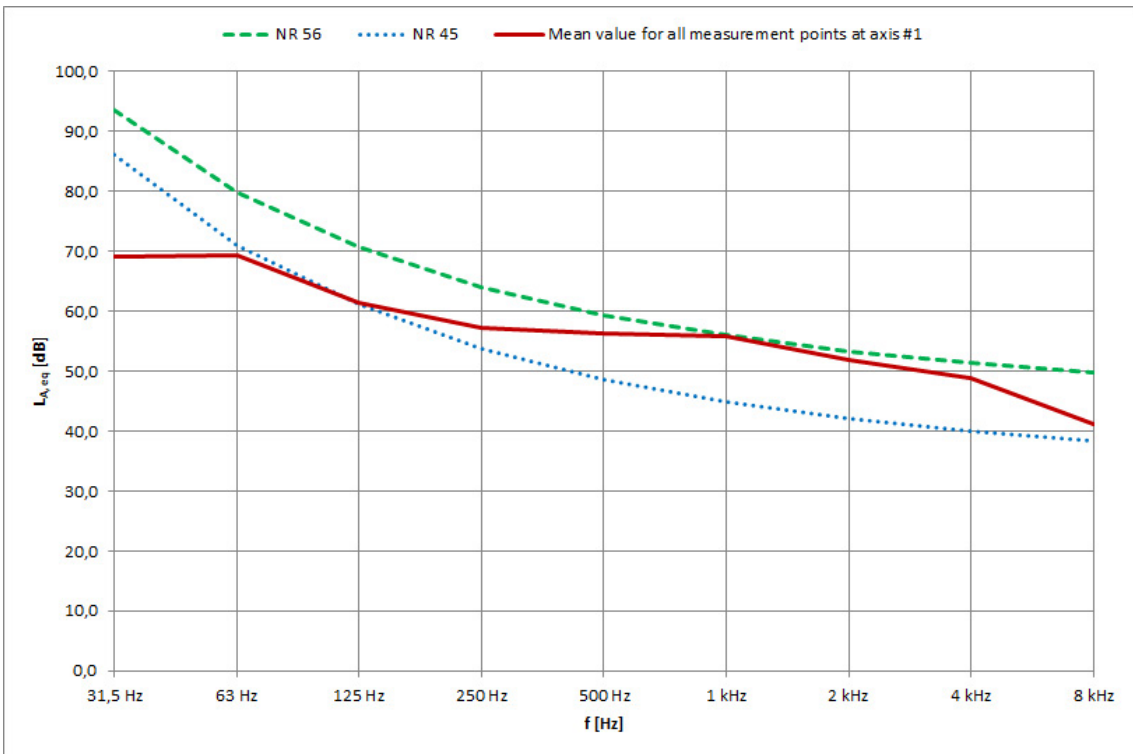

Fig. 21. Mean value SPLA weighted $\mathrm{L}_{\mathrm{A}, \text { eq }}$ at axis \#1 in the function of frequency vs NR56 and NR45 curves. Source: authors' own elaboration

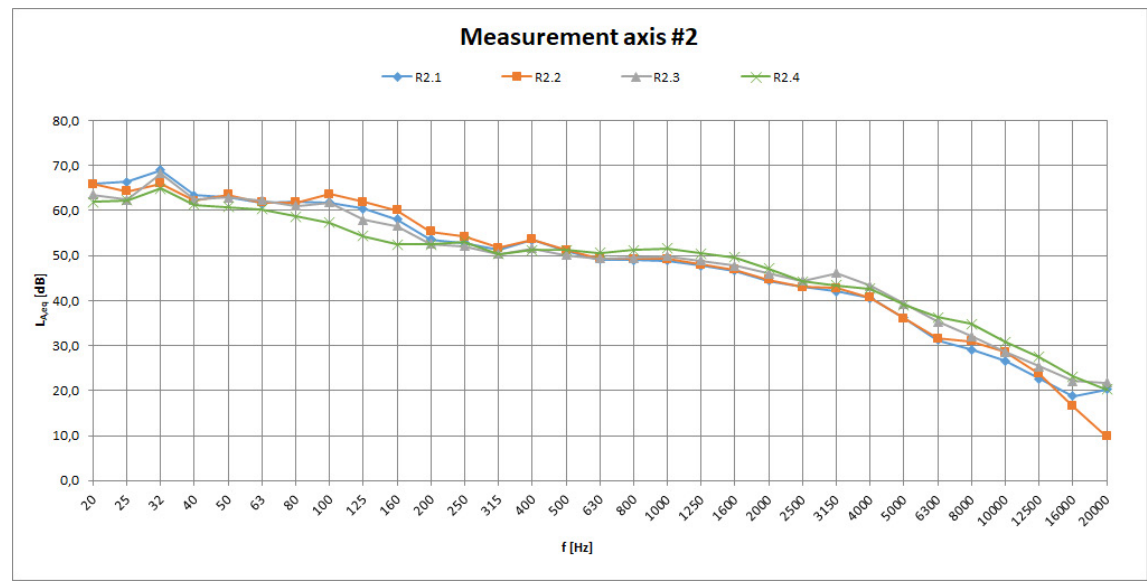

Fig. 22. Results of measurements done at every measurement point (R2.1 - R2.4) at axis \#2. Equivalent value (10 minutes) of SPL A weighted $\mathrm{L}_{\mathrm{A}, \text { eq }}$ in the function of frequency f. Source: authors' own elaboration

For the \#2 axis, the difference between the single-digit noise level values $\mathrm{L}_{\mathrm{A} \text {, eq }}$ (Fig. 11) for individual points does not exceed $2.5 \mathrm{~dB}$ A. This is mainly due to differences in medium and high frequencies (Figure 22). The exceedance of the permissible level the single-digit $\mathrm{L}_{\mathrm{A} \text {, eq }}$ value is $10 \mathrm{~dB}$ A. The noise measured in this axis does not exceed the NR 55 curve. No exceedances were observed for octaves 31,63 , and $8000 \mathrm{~Hz}$. 


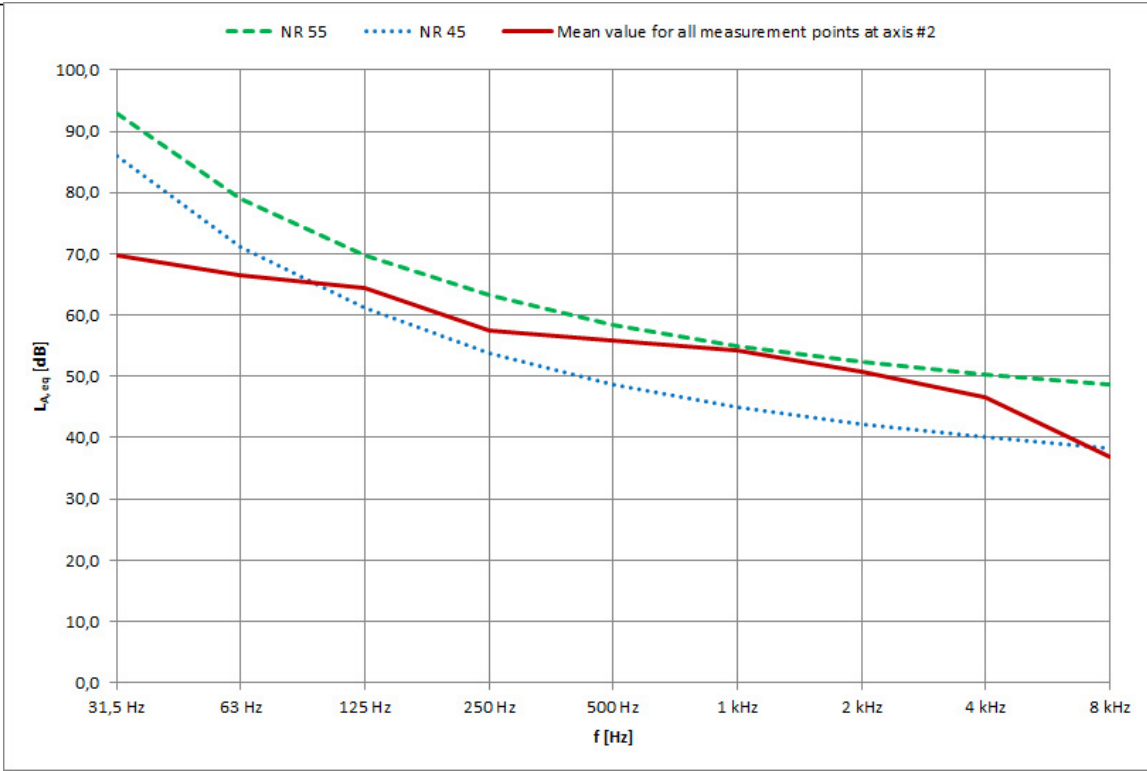

Fig. 23. Mean value SPL A weighted $\mathrm{L}_{\mathrm{A}, \text { eq }}$ at axis $\# 2$ in the function of frequency vs NR55 and NR45 curves. Source: authors'own elaboration

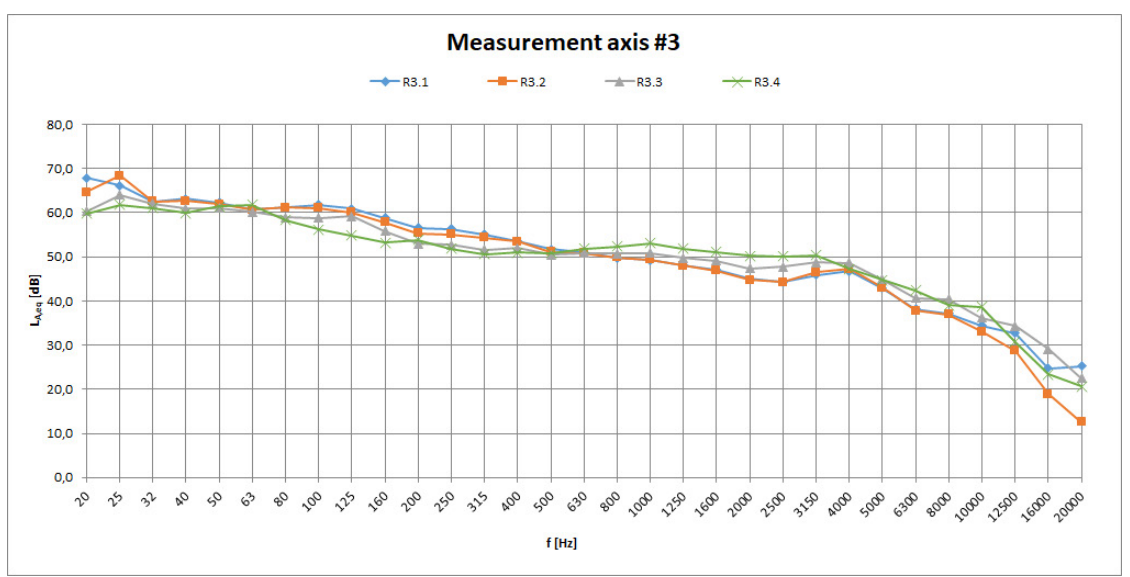

Fig. 24. Results of measurements done at every measurement point (R3.1 - R3.4) at axis \#3. Equivalent value (10 minutes) of SPL A weighted $\mathrm{L}_{\mathrm{A} \text {, eq }}$ in the function of frequency f. Source: authors' own elaboration

As already stated above, for the measurement axis \#3 top noise level of $\mathrm{L}_{\mathrm{A}, \mathrm{eq}}=69.12 \mathrm{~dB}$ A was recorded for point R3.4, which, as shown in Figure 24, results from higher levels for medium and high frequencies. Finally, this also results in the highest NR57 noise curve in the whole research. If for the axis \#3, the authors limit the analysis exclusively to the points under the flyover of its edge, then the single-digit $\mathrm{L}_{\mathrm{A} \text {, eq }}$ limit value would be exceeded by $12.32 \mathrm{~dB}$ but the averaged noise measured in three points on the R3.1 to R3.3 axes would still be described by the NR57 noise curve. Thus, for this axis, the noise requirements are exceeded by $12 \mathrm{~dB}$ A. 




Fig. 25. Mean value SPLA-weighted $\mathrm{L}_{\mathrm{A}, \text { eq }}$ at axis \#3 in the function of frequency vs NR57 and NR45 curves. Source: authors' own elaboration

As already noted, when analyzing Figure 19, for point R4.3 the noise level was much higher than for the other measurement points on this axis. The noise frequency characteristics presented in Figure 26 indicate that noise levels mainly increased in the high-frequency range. This is due to the proximity of large concrete pillars, which reflect sound waves, as already mentioned. The average noise spectrum on the \#4 axis did not exceed the NR54 noise curve (Figure 27). The NR45 curve was exceeded for the octave bands from $125 \mathrm{~Hz}$ to $8 \mathrm{kHz}$.

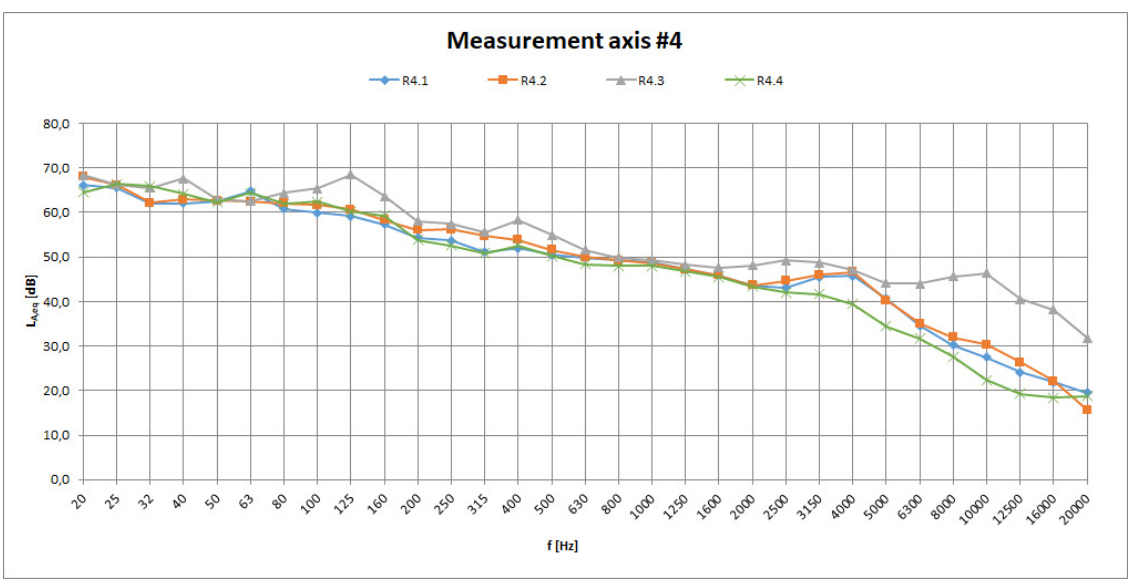

Fig. 26. Results of measurements taken at every measurement point (R4.1 - R4.4) at axis \#4. Equivalent value (10 minutes) of SPL A weighted $\mathrm{L}_{\mathrm{A}, \text { eq }}$ in the function of frequency f. Source: authors' own elaboration 


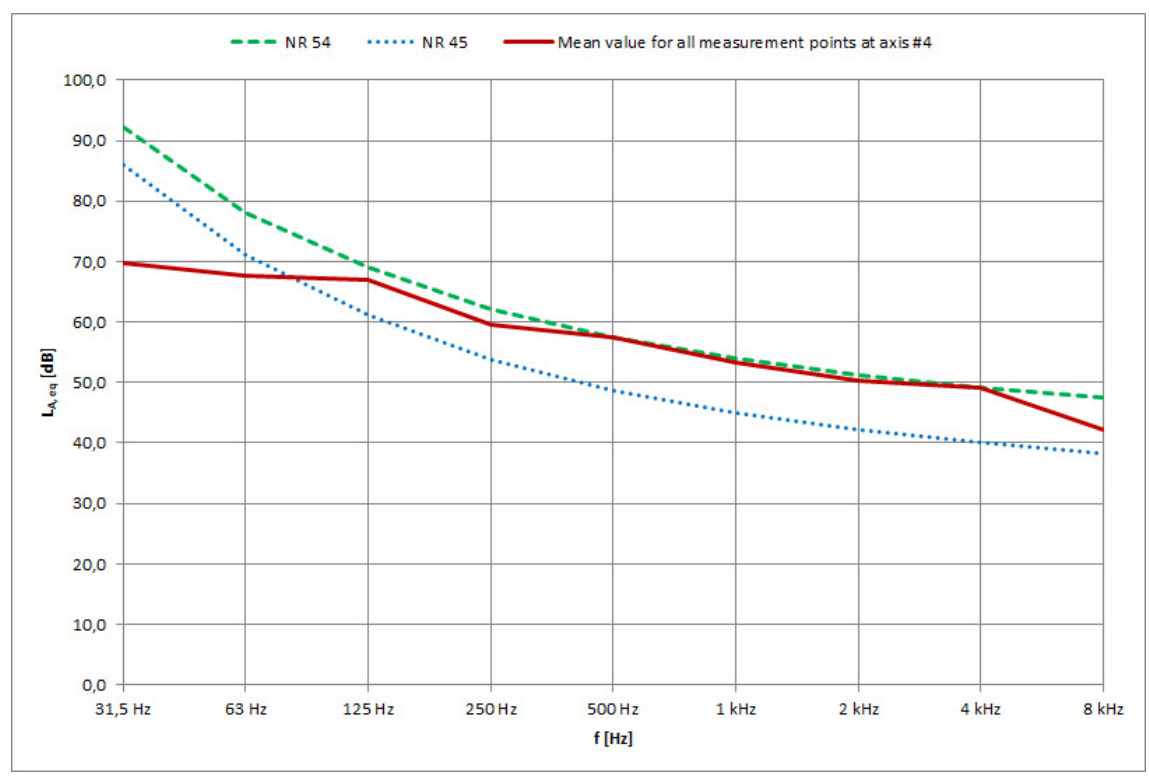

Fig. 27. Mean value SPLA weighted $\mathrm{L}_{\mathrm{A}, \text { eq }}$ at axis $\# 4$ in the function of frequency vs NR54 and NR45 curves. Source: authors' own elaboration

\section{Discussion}

The presented research differs significantly from previous studies on the use of bridge underspace as it is a multidisciplinary approach that brings together the research and design experience of acousticians and architects. Most researchers examining the utilization of the leftover spaces of overpasses focus mainly on land use and spatial forms [12] - [23]. None of them address the initial acoustic conditions of a given space in terms of possibilities of acoustic adaptation for outdoor public events. Therefore, this study appears to be the first to conduct research on the use of bridge underspace in the context of acoustics. The presented findings add substantially to our understanding of initial acoustic conditions of a general model of the bridge underspace, e.g. relationship between the geometry of the urban bridge underspace and the noise levels. The situation widely regulated and analysed is the case of traffic noise generated at the level of a communication route [24] - [27] and [31], [32]. However, this work offers one of the first investigations devoted to analyzing the impact of traffic noise on an overpass on the areas below it. Thus, the authors had to come up with their own method of assessment of the acoustic conditions of the examined bridge underspace as there are currently no binding legal acts or recommendations, which would explicitly specify criteria to assess the baseline situation regarding noise levels within it. For this reason, both equivalent acceptable noise levels (defined for recreational spaces in WHO recommendations [39] and Polish regulations [40]), as well as the family of NR (defined in ISO/R 1996:1971 [41]) were compared with noise levels measured at selected points of the examined bridge underspace.

As discussed in the Literature Review chapter, it was discovered that the only study focusing on acoustic climate of bridge underspace is the research reported by Chi-Chwen et al. [28]. However, it has totally different assumptions. While Chi-Chwen et al. examine only the effects of noise coming from the nearby major traffic route reflected on the overpass underside, our aim was to examine general acoustic climate of the space located under an overpass in 
order to assess the possibility of adapting them for outdoor public events. In order to avoid a reflection of traffic noise on the overpass underside and at the same time to distinguish the study from the one mentioned above [28] the chosen site for the study didn't have major traffic route in its vicinity, except the one located on the flyover.

Given these points, comparing to earlier findings, this research appears to be pioneering and the results can be used as valuable input for further studies on this topic.

\subsection{Managerial recommendations}

Summing up, the results allow to make the following preliminary assumptions for the planned further studies on the revitalization possibilities of bridge underspaces:

1. Noise limit values are generally not exceeded for low-frequency ranges, which makes the expected noise reduction achievable.

2. In the medium to high-frequency range noise limits are mostly exceeded in the $125 \mathrm{~Hz}$ to $4 \mathrm{kHz}$ band.

3. The vertical and horizontal reflecting surfaces should be covered with materials with possibly high sound absorption coefficient for medium and high frequencies. Ideally, these should be solutions in the acoustic absorption class A.

4. In the research area, noise limit values were not exceeded by more than $12 \mathrm{~dB}$ A. This allows us to assume that it is possible to reduce noise levels as much as to meet the requirements for recreational and sports spaces.

5. It is advisable to minimize the number of paved surfaces and thus maximize the amount of unpaved and maximally green surfaces.

6. Areas for which the distance between the flyover underside and the ground is smaller are likely to exhibit lower noise levels than those spaces where this distance is greater, provided that the volume of traffic, and thus the source of noise is the same and the spatial conditions on the flyover sides are also the same.

In subsequent research the authors plan to verify the following solutions and hypotheses:

7. Creation of vertical screens for noise reduction that would cut off the space beneath the flyover to improve the acoustic conditions of such enclosed bridge subspaces, in particular:

a. Reduction of noise levels to the required values.

b. Reduction of reverberation time.

c. Increase in the speech intelligibility factor.

8. Verification of the relationship between noise reduction efficiency in the bridge underspace as a result of introducing acoustic noise barriers compared to introducing noise-absorbing elements.

9. Verification of the conclusions presented above with other bridge underspaces.

The analysis of acoustic climate in bridge underspaces shows that the given starting conditions depend not only on the characteristics and location of the source of sound and vibrations, but also on the environment and the urban and architectural elements. Therefore, when analyzing the bridge underspace for a new investment in the existing condition, a detailed analysis seems desirable. It may include the following elements: 
- field measurements of the so-called background noise to identify the physical acoustic properties of a given area,

- checking the location of noise sources in a given area, for example by using an acoustic camera,

- field measurements of ground vibrations at a planned investment site (especially in the vicinity of rail routes) using an accelerometer (acceleration/vibration sensor); the so-called vibration diagnostics,

- analysis of the results obtained.

From the acoustic point of view, bridge underspace would be analyzed differently, depending on the intended use; whether it will be developed or used as open space. Due to the acoustic characteristics, the bridge underspace not limited by any barrier is a limited built urban space (with the upper limit being the bridge and the lower limit being surface area beneath it), whereas in design practice (excluding the very peculiar case of an outdoor theatre) the sole aim is to reduce noise and vibration levels. Such an interior should not be completely isolated from the environment. However, when designing entirely enclosed spaces, the researchers are dealing with an architectural and construction interior; therefore, they should seek to achieve specific vibro-acoustic conditions by isolating it from ambient noise and vibrations, as well as appropriate interior acoustics parameters resulting mostly from the interior shape, dimensions, and finish. Both the presented variants of the acoustic modernization and spatial transformation of the bridge underspace will be subject to further research.

\section{Conclusions}

The research resulted in gathering unique data from the pilot case study examining the noise conditions under the flyover resulting from road traffic taking place on chosen flyover of Milenijny Bridge crossing over the Odra River in Wrocław. Taken together, these findings are basis for formulating hypotheses and preliminary assumptions for the planned further and broader studies on the revitalization possibilities of bridge underspaces. The conclusions that could have been drawn from the analysis of these results allow us to make more detailed assumptions for creating public spaces in bridge underspace that meet noise requirements for recreational and sports venues, or a local agora. The results of this study already show that on the basis of the presented measurement data, it is possible to assess the plausibility of such kind of investment and to select an optimal location for them and a form and functional program of the planned facility, and to propose optimal noise and anti-vibration safeguards.

\section{References}

[1] Bibri S.E., Krogstie J., Kärrholm M., "Compact city planning and development: Emerging practices and strategies for achieving the goals of sustainability", Developments in the Built Environment, vol. 4, 100021, 2020. https://doi.org/10.1016/j.dibe.2020.100021

[2] Bodnar J., "Reclaiming public space", Urban Studies, vol. 52(12), 2015, pp. 2090-2104. https:// doi.org/10.1177\%2F0042098015583626

[3] Barron P. and Mariani M., Terrain Vague: Interstices at the Edge of the Pale. London: Routledge, 2013.

[4] Komarzyńska-Świeściak E., Conditions and forms of activation of spaces located under elevated transport routes at the turn of the $20^{\text {th }}$ and $21^{\text {st }}$ centuries. Wrocław: Oficyna Wydawnicza Politechniki Wrocławskiej, typescript, in press. 
[5] Bauer C. et al., Under the elevated. New York: Design Trust for Public Space, 2015.

[6] Chohan A.H., "Infrastructure Development and Implication of Negative Spaces in City Centers", GSTF Journal of Engineering Technology, 3: (1), 2014, pp. 53-60. http:// doi. org/10.5176/2251-3701_3.1.110

[7] Duarte, G. "Infrascapes: Interstitial Enclaves of the Unplanned", in 306090 09: regarding public space, eds. Lyster C. et al.., New York: Princeton Architectural Press, 2006, pp. 72-79.

[8] Saaty T.L., De Paola P., "Rethinking Design and Urban Planning for the Cities of the Future", Buildings, 2017, vol. 7, 76. https://doi.org/10.3390/buildings7030076

[9] Barron P., Mariani, M., Terrain Vague: Interstices at the Edge of the Pale. London: Routledge, 2013.

[10] Barański S., „Projekt 103”, photography. Availble: https://www.facebook.com/projekt103/photos/ pcb.1826727410805002/1826727207471689/ [Accessed: 30 Oct 2021]

[11] Komarzyńska-Świeściak E., Kirschke P., "The issue of integration of elevated transport routes in the areas of historic polish cities. Example of the modernization of a cross-city railway line in the Śródmieście district of Kraków", Technical Transactions, 2019, vol. 10, pp. 35-58. https://doi.org/ 10.4467/2353737xct.19.106.11030

[12] Sheng J., Xu H., Zheng J., Luo M.,Zhou X., "Commercial Value Assessment of "Grey Space" under Overpasses: Analytic Hierarchy Process", Advances in Civil Engineering, vol. 2018, Article ID 4970697, 2018. https://doi.org/10.1155/2018/4970697

[13] Weize X., “The Bottom Space Usage Model And Characteristic Of Tokyo's Viaduct", Planners, vol. 33, 2017, pp. 101-105.

[14] Snapir A., A research on the inhabited viaduct architecture in Tokio. Focusing on its contribution to the vitality of the city centre. Tokyo: University of Tokyo, 2012.

[15] Qamaruz-Zaman, N., Samadi Z. and Azhari N. Opportunity in Leftover Spaces: Activities Under the Flyovers of Kuala Lumpur. Procedia - Social and Behavioral Sciences. 68. pp. 451-463. 10.1016/j.sbspro.2012.12.241. 2012.

[16] Murray P. and Stevens M., Living bridges: Inhabited Bridge - Past, Present and Future. Londyn: Prestel, 1996.

[17] Piekarski J., Living Bridges. Warszawa: Związek Mostowców Rzeczypospolitej Polskiej, 2007.

[18] Wesołowski J., Railway in the urban space - problems of integration. Gliwice: Silesian University of Technology, 1997.

[19] Hauck Th., Keller R., Kleinekort V. (eds.), Infrastructural Urbanism. Addressing the In-between. Berlin: DOM publishers, 2011, pp. 93-108.

[20] Crisman P., "Interstices: Appropriation of Transportation Infrastructure in the Post-Industrial City", in Heteropolis: Immigration, Ethnicity and the American City, ed. Wells-Bowie L., Washington: ACSA Press, 2000, pp. 74-80.

[21] Duarte G., "Infrascapes: Interstitial Enclaves of the Unplanned", in Tom 306090 09: regarding public space, eds. Benites C. et al., New York: Princeton Architectural Press, 2005, pp. 72-79.

[22] Buchner A., Bridge routes in the cityscape. Warsaw-Łódź: Wydawnictwo Naukowe PWN, 1982.

[23] Łapko A., "Functional transformation of bridges and other engineering structures", Technical Transactions, vol. 15, 2010, pp. 235.

[24] Jagniatinskis A. et al., "Annual Assessment of Noise Generated by Road Traffic using Measurements", Procedia Engineering, vol. 187, 2017, pp. 614-619. https://doi.org/10.1016/j. proeng.2017.04.421

[25] Bohatkiewicz J., "Protection against traffic noise in urban areas in relation to noise control plans", Budownictwo i Architektura, vol. 13(4), 2014, pp. 075-082. https://doi.org/10.35784/ bud-arch.1708 
[26] Motylewicz, M. and Gardziejczyk, W. (2014) "Road traffic noise in areas surrounding intersections”, Budownictwo i Architektura, vol. 13(1), 2014, pp. 137-147. https://doi.org/10.35784/ bud-arch.1934

[27] Nurzyński J., "Acoustical assessment of urban residential environment”, Budownictwo i Architektura, vol. 13(4), 2014, pp. 033-040. https://doi.org/10.35784/bud-arch.1690

[28] Lin C-C. et al., "Impact and Control of Reflected Noise from an Overpass Bottom", Applied Sciences, 2018, vol. 8(10):1908. https://doi.org/10.3390/app8101908

[29] Wai Ming T., Chung A.W.L., Schulte-Fortkamp B., "Soundscape design of an open-air concert venue using virtual reality technologies", in Proceedings of meetings on acoustics Acoustical Society of America, 2017, 30. 040013. https://doi.org/10.1121/2.0000829

[30] Minell G. et al., "Prediction of off-site noise levels reduction in open-air music events within densely populated urban areas", in INTER-NOISE and NOISE-CON Congress and Conference Proceedings, vol. 259 (5), 2019, pp. 4450-4459.

[31] Benocci R. et al., "Accuracy of the Dynamic Acoustic Map in a Large City Generated by Fixed Monitoring Units", Sensors, 2020, vol. 20, 412. https://doi.org/10.3390/s20020412

[32] Do Nascimento E.O. et al., "Noise prediction based on acoustic maps and vehicle fleet composition", Applied Acoustics, 2021, vol. 174, 107803. https://doi.org/10.1016/j.apacoust.2020.107803

[33] Directive 2002/49/EC of the European Parliament and of the Council of 25 June 2002 relating to the assessment and management of environmental noise, Official Journal L 189, 2002, P.0012-0025.

[34] Wysocki T., An unusual project by a jazzman: concerts under Wrocław's bridges. Available: https://www.wroclaw.pl/extra/niezwykly-projekt-jazzmana-koncerty-pod-wroclawskimi-mostami [Accessed: 30 Oct 2021]

[35] Hartley J., "Case study research", in Essential Guide to Qualitative Methods in Organizational Research, eds. Cassell C., Gillian, S., London: Sage Publications Ltd, 2004, pp. 323-333.

[36] Yin R.K., Case Study Research: Design and Methods, Thousand Oaks: Sage Publications, 1994.

[37] Harrison H. et al., "Case Study Research: Foundations and Methodological Orientations", Forum Qual. Soc. Res., 2017, 18. https://doi.org/10.17169/fqs-18.1.2655

[38] Flyvbjerg B., Case Study. In The Sage Handbook of Qualitative Research. $4^{\text {th }}$ ed., eds. Denzin, N.K., Lincoln, Y.S., Thousand Oaks: Sage:, 2011, pp. 301-316.

[39] Berglund B., Lindvall, Th., Schwela, D.H. Occupational and Environmental Health Team. Guidelines for community noise, https://apps.who.int/iris/handle/10665/66217, 1999 (accessed on 6 July 2021).

[40] Decree of Minister of Environment of 15 October 2013 on publishing the consolidated text of the Regulation of the Minister of the Environment on permissible levels of noise in the environment, Journal of Laws, No 120, item 826. Warsaw, 2014.

[41] ISO 1996-2:2017 Recommendation. Acoustics - Description, measurement and assessment of environmental noise - Part 2: Determination of sound pressure levels.

[42] Gottlob D., "Regulations for community noise", Noise/News International, December 1995, pp.223-236.

[43] Kozłowski P. Z., "Acoustics and Stage Technology Solutions at New Home for Polish National Radio Symphony Orchestra in Katowice", in Progress of acoustics, ed. Bismor D., Gliwice: Polish Acoustical Society 2017, pp. 277-288.

[44] Mehta M.M., Johnson J., Rocafort J., Architectural Acoustics Principles and Design. New Jersey: Prentice Hall, 1998.

[45] Mapp P., Audio System Designer. Technical Reference. Kiddermnister: Klark-Teknik, 1985.

[46] Biprogeo-Projekt LLC, Kieleckie przedsiębiorstwo Robót Mostowych Skanska joint-stock company. Crossing of the Oder River with access roads within the inner ring road from Legnicka Street to Osobowicka Street in Wroclaw, Wrocław 2002 [Building Permit Documentation] (in Polish). 